Portland State University

PDXScholar

$1-1-2011$

\title{
Teaching Intonation Patterns through Reading Aloud
}

Micah William Park

Portland State University

Follow this and additional works at: https://pdxscholar.library.pdx.edu/open_access_etds Let us know how access to this document benefits you.

\section{Recommended Citation}

Park, Micah William, "Teaching Intonation Patterns through Reading Aloud" (2011). Dissertations and Theses. Paper 267.

https://doi.org/10.15760/etd.267

This Thesis is brought to you for free and open access. It has been accepted for inclusion in Dissertations and Theses by an authorized administrator of PDXScholar. Please contact us if we can make this document more accessible: pdxscholar@pdx.edu. 
Teaching Intonation Patterns through Reading Aloud

\author{
by
}

Micah William Park

A thesis submitted in partial fulfillment of the requirements for the degree of

Master of Arts
in
Teaching English to Speakers of Other Languages

Thesis Committee:

Tucker Childs, Chair

John Hellermann

Jennifer Stenseth

Portland State University

(C)2011 


\begin{abstract}
This study investigated whether East Asian learners of English $(n=8)$ studying in the US acquired more accurate intonation patterns (compared to native-speaker norms) after receiving five weeks of tutoring focusing on four basic intonation patterns (definite statements, wh-questions, yes/no questions, and tag questions) and using oral reading as the primary practice technique. The study also assessed the students' affective reaction to the teaching method through interviews. The study found that the learners significantly improved their intonational accuracy (based on the judgments of three native speakers who listened to single-sentence recordings $[\mathrm{n}=868]$ from questionnaires, exit interviews, and pre- and post-tests) and that they were generally amenable to the teaching technique.
\end{abstract}




\section{Table of Contents}

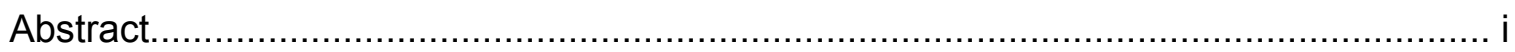

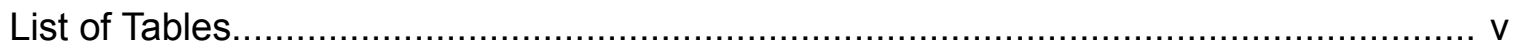

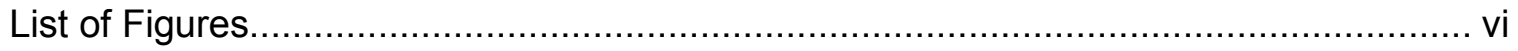

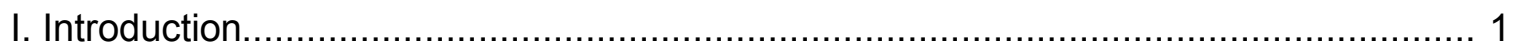

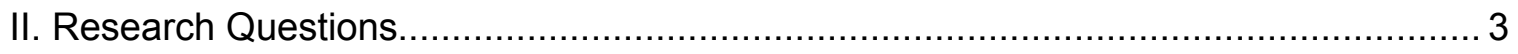

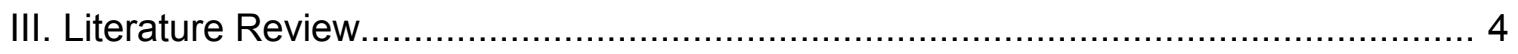

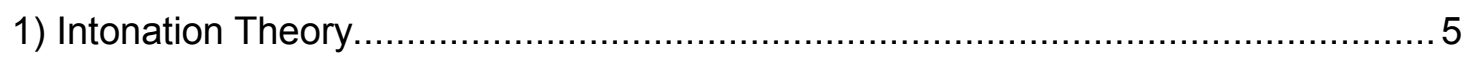

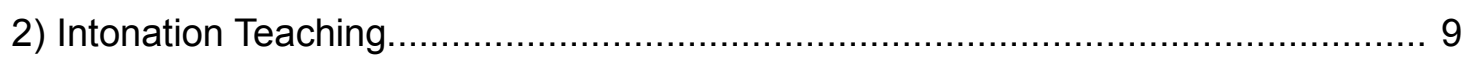

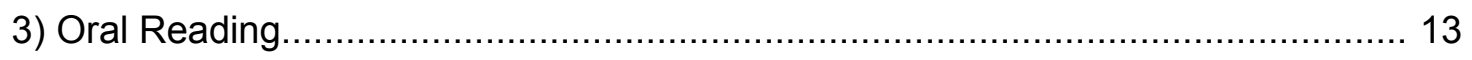

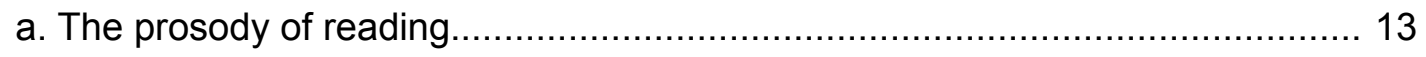

b. Oral reading and spontaneous speech................................................ 16

4) Teaching Pronunciation through Oral Reading......................................19

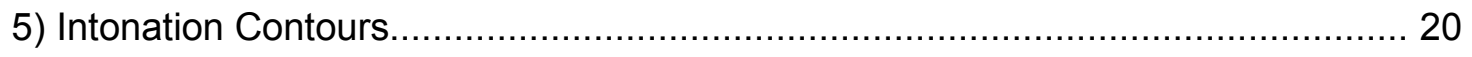

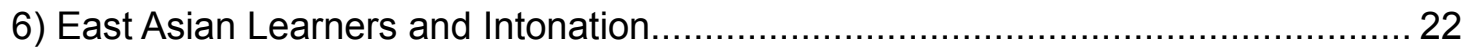

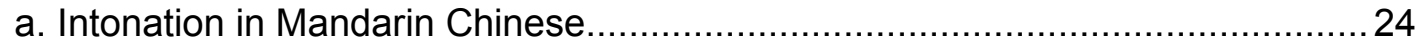

b. Intonation in Cantonese..................................................................... 26

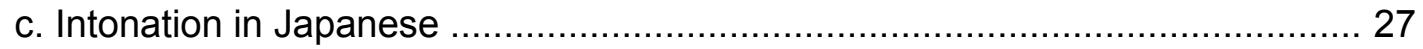

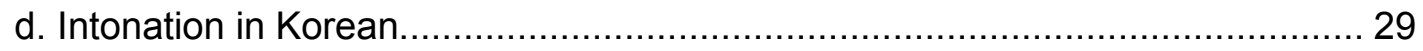

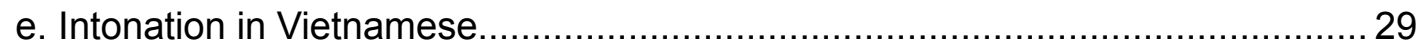

7) Affect, Motivation, and English Language Teaching in East Asia ......................31

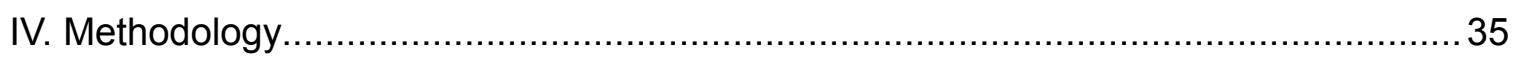

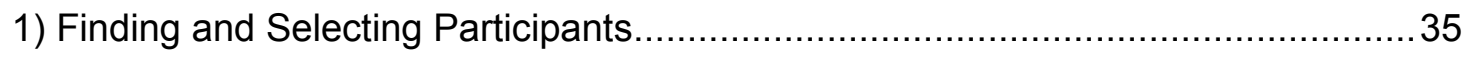




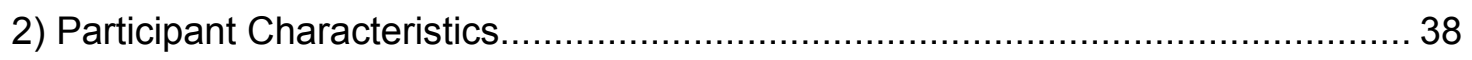

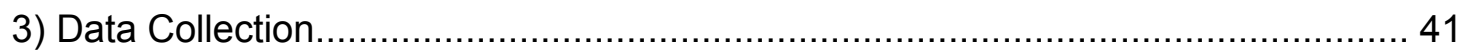

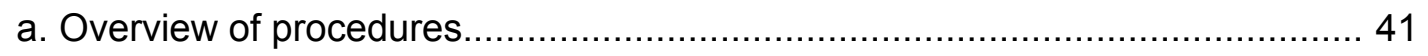

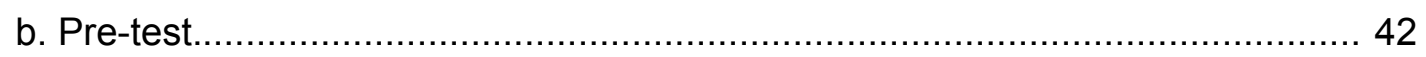

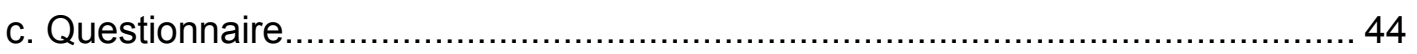

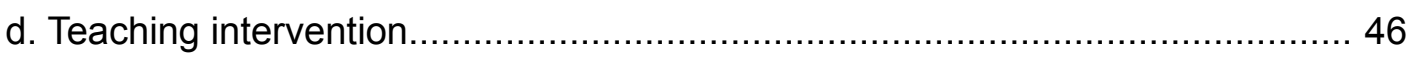

e. Post-test and exit interview...................................................................... 50

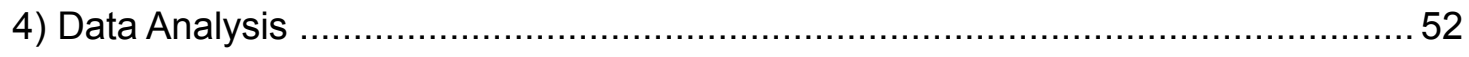

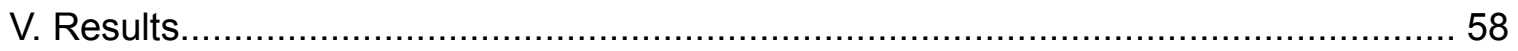

1) Research Question 1: Intonational Accuracy Improvement..............................58

2) Research Question 2: Participant Attitudes and Perceptions...............................65

a. Perception of intonational accuracy improvement............................................. 66

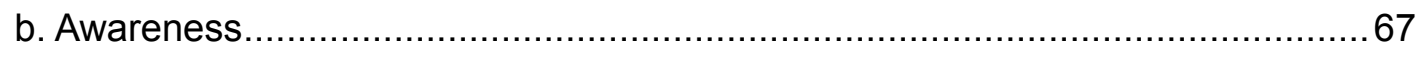

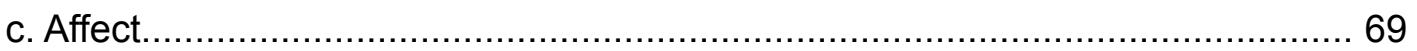

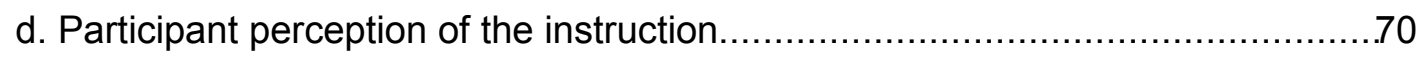

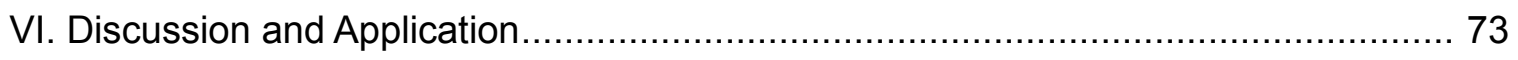

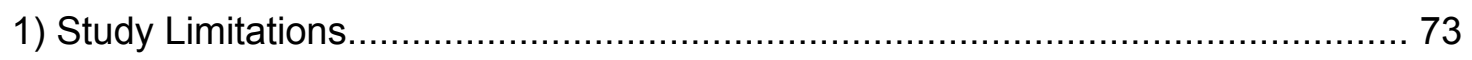

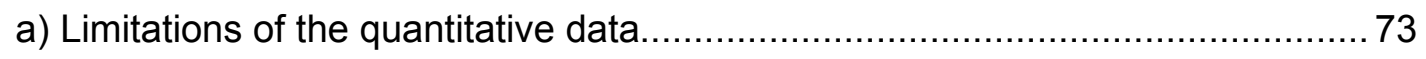

b) Discourse context as a complicating factor.................................................. 77

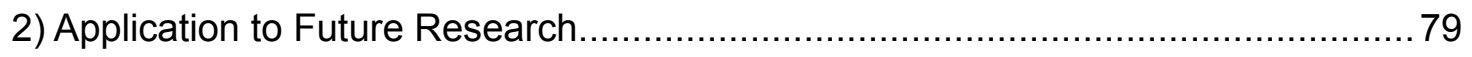

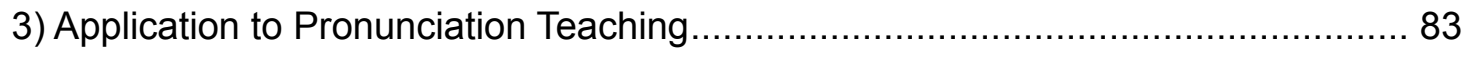

VII. Conclusion

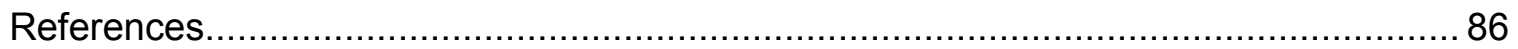




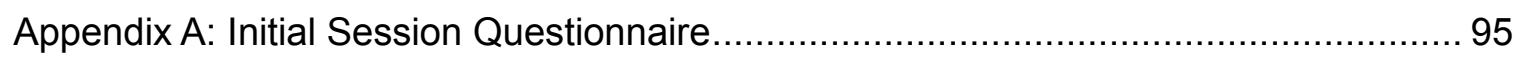

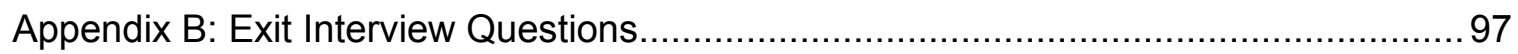

Appendix C: Description of a typical tutoring session....................................... 99

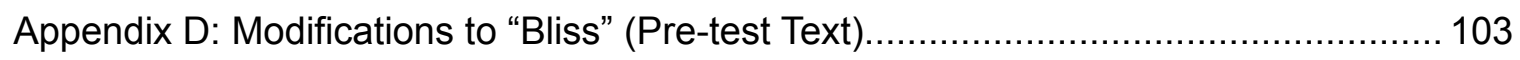




\section{List of Tables}

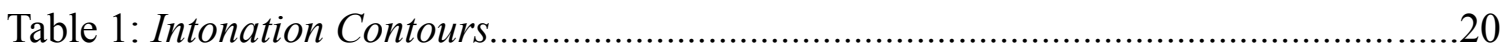

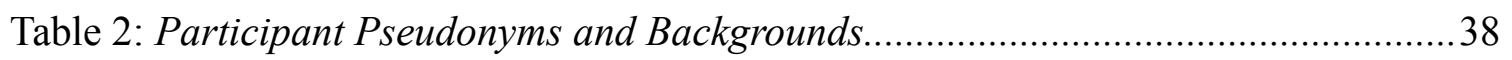

Table 3: Levels of the IELP Courses the Participants were Enrolled in...........................39

Table 4: Sentence type counts for "Hills Like White Elephants "....................................44

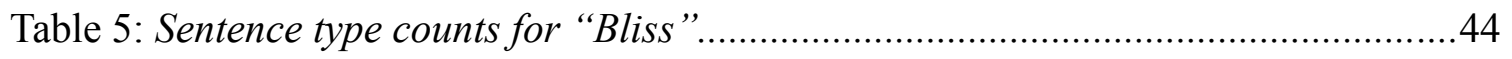

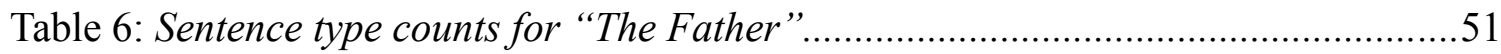

Table 7: Sentence type counts for an excerpt from “An Ordinary Day, with Peanuts”....51

Table 8: Tokens counts categorized by participant, data source, and sentence type.........59

Table 9: Intonational accuracy frequency by sentence type comparing pre- and post-

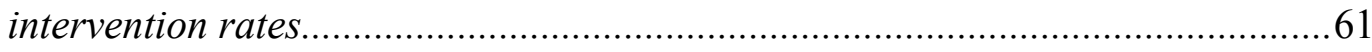

Table 10: Intonational accuracy frequency by sentence type comparing pre- and post-test

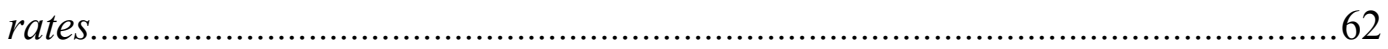

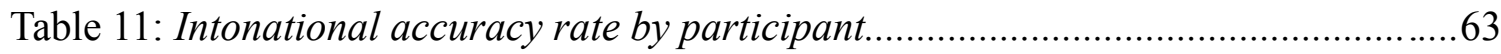

Table 12: Averages of intonational accuracy rates by participant................................64

Table 13: Intonational accuracy rates by participant, excluding small data sub-sets......65

Table 14: Participant feelings about studying English intonation (exit interview question

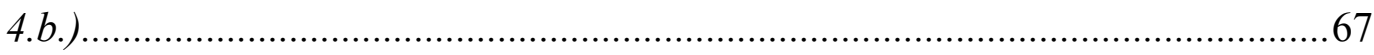

Table 15: Participant feelings about oral reading (exit interview question 4.a.).............68 


\section{List of Figures}

Figure 1: Example intonation contour drawing for a declarative sentence......................48 


\section{Introduction}

Can language teachers use oral reading to teach language learners the intonation system of another language? It has been suggested that oral reading, also known as reading aloud, is useful for practicing intonation (Underhill, 1994, p. 91), but a search of the literature reveals no studies that have addressed this use of oral reading. This study investigated if explicit pronunciation instruction using oral reading practice can improve students' intonation by making it more native-like.

Following the suggestions in a frequently cited pronunciation instruction textbook (Celce-Murcia, Brinton, \& Goodwin, 1996), I introduced students to a set of the most common intonation contours, which they practiced by reading aloud. Explaining to students the rules of pronunciation and then having the students practice applying these rules to their pronunciation is known as "explicit pronunciation instruction." It is known that explicitly teaching pronunciation can be effective in improving a student's pronunciation (Morley, 1994, p. 67; Couper, 2003), so the question is what effect, if any, explicit intonation instruction in the form of oral reading practice has on intonational accuracy. To assess intonational accuracy, I recorded all the participants reading aloud before and after the teaching intervention, comparing their production in both cases to native-speaker norms.

Motivation plays an important role in achieving native-like pronunciation (Bongaerts, van Summeren, Planken, \& Schils, 1997, p. 462). Therefore, how receptive the participants were to learning through oral reading was a factor that this thesis also sought to evaluate. The receptivity of students to the oral reading technique was assessed 
in a more qualitative way through post-intervention interviews (which a colleague administered after the completion of the tutoring sequence). I also collected background information on the participants' language learning experiences and attitudes prior to the teaching intervention through questionnaires (which I administered at the initial tutoring sessions).

In the first chapter of this thesis, I present the research questions that guided the study. In the literature review, I look at what previous research has said about intonation, oral reading, pronunciation teaching, and the particular difficulties that East Asians face in learning English. I also address the effect of affect or motivation on East Asian students in regard to attaining native-like pronunciation. In the third chapter, I describe and justify the study's methodology in terms of participants, data collection, and data analysis. I explain and discuss the results of the study in the fourth chapter, and in the fifth chapter I conclude by detailing the implications of this study and suggesting further directions for similar studies. I relate the study findings back to the original motivation for undertaking this study and summarize the importance of this study in the final chapter. 


\section{Research Questions}

1. When tutoring East Asian English language learners (ELLs), does oral reading practice in the framework of explicit pronunciation teaching improve the learners' intonational accuracy, with "accuracy" interpreted as similarity to native-speaker norms?

2. What are East Asian ELLs' attitudes toward the instructional technique of oral reading?

a) Do these ELLs perceive that this teaching technique has improved their intonation?

b) Do these ELLs report that they are more aware of their pronunciation as a result of this teaching?

c) Do these ELLs enjoy reading aloud? 


\section{Literature Review}

How effective is oral reading as a teaching technique? Very few studies have investigated the use of oral reading to practice native-like prosody or its components: stress, rhythm, and intonation. In fact, until recently, prosody was not explicitly taught. Pronunciation teachers have focused their efforts on the segmental level (that is, consonants and vowels), even though prosodic accuracy has been shown to be more important for listener comprehensibility than segmental accuracy (Celce-Murcia, et al., 1996, p. 131). In other words, speech that is more accurate in terms of prosody is easier to understand than speech that is more accurate in terms of segmentals. A focus on prosody has generally been recognized as greatly improving comprehensibility (Avery \& Ehrlich, 1992, p. 106). Consequently, the recent trend in language teaching has been for instructors to concentrate more on stress, rhythm, and other prosodic aspects of learners' speech.

Oral reading practice is one tool that teachers could use to improve their students' intonation, but how effective is it for improving intonation? In this literature review, I first consider intonation theory and then intonation teaching in order to show how linguists believe intonation to function and to explain why I chose to teach intonation in the way that I did. Next, I look at the prosody of oral reading and how oral reading speech may be different from spontaneous speech. With this information about the nature of oral reading in mind, I next explain the advantages and disadvantages of using oral reading in the language learning classroom, thereby showing why I chose to focus on oral 
reading during the teaching intervention. I then describe the intonation contours that I taught in this study. After this description, I turn to describing motivational and attitudinal aspects of the participants' backgrounds that may have influenced the outcome of the teaching intervention. Next, I look at the intonation systems of the participants' first languages in order to both show how intonation teaching is often necessary for ELLs with these L1s and in order to explain variations in the English intonation of the different participant groups. Finally, since all of the participants in the study were from East Asia, I consider the common motivational and affective factors that affect East Asian students, thereby accounting for factors that may have influenced the students' responses to the teaching intervention.

\section{1) Intonation Theory}

Intonation has been characterized as "the rising and falling of the voice to various pitch levels during the articulation of an utterance" (Celce-Murcia, et al., 1996, p. 184) or, more simply, "the pitch pattern in a sentence" (Ladefoged, 2006, p. 23). Intonation patterns consist of sequences of tones or pitches. For the purposes of this study, "pitch" refers to the perceptual correlate of fundamental frequency, and a particular pitch on a syllable is a "tone.” Different intonation patterns perform different linguistic functions, such as marking specific sentence types and indicating thought group boundaries (CelceMurcia, et al., 1996, p. 200-210). Although intonation patterns also perform paralinguistic functions such as indicating emotional states (Bolinger, 1986, p. 27) or membership in a social group (Chun, 2002), only the linguistic functions of intonation were considered in 
this study, concentrating on intonation contours associated with certain sentence types (definite statements, yes/no questions, wh-questions, and tag questions).

Linguists such as Ladd (1980) have pointed out the problems with assuming that speakers choose intonation contours based on grammar alone. Rather, Ladd (1980) claimed that intonation patterns can be thought of in much the same way as lexical words. Intonation contours have "an abstract context-free element of meaning, which produces specific nuances in specific contexts" (p. 141, citing Liberman, 1978). Intonation contours, therefore, cannot be separated from their context without losing some of their meaning. However, teaching ELLs every nuance of intonation is not possible, but it is possible to teach the general and salient rules of intonation.

Syntactically-defined contours are salient, and it is possible to consider syntax the default determining function for intonation, although discourse functions may overrule it. Following the recommendations of Celce-Murcia et al. (1996), I chose to focus the teaching intervention component of this thesis on several syntactically-defined contours, which are defined further in the intonation contours section of this literature review. In addition, I concentrated on only syntactically-defined sentence types in analyzing the preand post-tests in order to limit the research for this thesis to more easily observed phenomena.

Considering the discourse-based aspects of intonational meaning would have required the analysis of the context of each utterance, and doing so would have taken away the focus of this thesis from observing the effect of the teaching intervention to 
Running head: TEACHING INTONATION PATTERNS... 7

determining which contour would be appropriate in which context. For example, some of the participants read "The Collection," a play by Harold Pinter. In one scene, James, speaking to Bill, asserts, "You're a wag, aren't you? I never thought you'd be such a wag" (Pinter, 1977, p. 133). Given the context of the scene in that James believes that Bill slept with his wife and is becoming exasperated by Bill's attempts to deny it, James would be likely to use a falling intonation on the tag question "aren't you?" to express the force of his assertion that Bill is a wag. Wells (2006) called this kind of intonation on a tag question an "insistent fall" (p. 49). The syntax of James' statement could be used for either a "true question" tag or an assertive tag, but the context in which James feels that he must assert his opinion of Bill would probably cause James to select a falling contour, thereby making his utterance assertive. This example illustrates the complications of considering the discourse functions of intonation. Syntactically determined contours compromise a more tractable set, and they are also important enough to warrant teaching them to English language learners (ELLs).

There is general agreement that English has a set of intonation patterns which speakers use for both linguistic and paralinguistic purposes. Furthermore, intonation is not isolated from other linguistic phenomena. Stress, rhythm, and accent interact with intonation and determine where and how changes in intonation take place. Bolinger's (1986) distinction between stress and accent is useful here. In English, some syllables have stress, that is, they can be longer, louder, and at a higher pitch compared to unstressed syllables. In terms of rhythm, English is, roughly speaking, a stress-timed 
language. When we speak English, we space the stressed syllables apart at approximately the same intervals.

In addition to using timing syllables based on stress, speakers accent or emphasize some stressed syllables (Bolinger, 1986, p. 14-15). Accent is important for this thesis because the accented syllable is where the important intonational information is anchored. The fundamental frequency of an accented syllable (which I call "pitch") is the most important indicator of accent in English (Bolinger, 1986, p. 21). The rhythm of English is an important concern for learners of English because pitch changes happen more often on stressed syllables. To be more specific, English speakers place an accent on one syllable in the intonational phase. This syllable is from the word that is most important for the meaning. If the word has two or more syllables, the accent is placed on the stressed syllable (Wells, 2006, p. 93). Not all stressed syllables are accented, but "the stressed syllable is the one that carries the potential for accent" (Bolinger, 1986, p. 15). The accent is manifested as the nuclear or primary tone of the intonation phrase (Wells, 2006, p. 93), hence the relevance of accent in teaching intonation to ELLs.

This study focused in particular on "boundary tones", also known as "terminals." If we consider only how intonation interacts with morphosyntax, intonation is most clearly shown at the ends of phrases, clauses, or sentence (Bolinger, 1986, p. 25). A boundary tone is "the tone associated with the very end $[\ldots]$ of an intonational phrase" (Ladd, 2008, p. 88). Boundary tones can be either high or low relative to the preceding 
tone(s) in the intonational phrase (Beckman \& Pierrehumbert, 1986). In the next section, I consider how boundary tones and intonation in general might be taught to ELLs.

\section{2) Intonation Teaching}

"Of course pronunciation is important - critically important - and especially if it is your pronunciation, as an ESL speaker, and people can't understand you!” (original emphasis retained; Morley, 1994, p. 66). English language teachers in recent years have begun to recognize the importance of explicitly teaching pronunciation, especially prosodic phenomena such as intonation (Morley, 1991, p. 492-495). Non-native-like intonation can easily lead to misunderstandings. One well-known example of native speakers (NSs) misinterpreting non-native speakers' (NNS') intonation was described in Gumperz (1982). In one incident, NNS cafeteria workers from the Indian subcontinent used a falling tone on the word "gravy" to ask if customers wanted gravy (p. 173-174). NSs perceived the workers to be surly because the native-like intonation would have been a rising tone on "gravy." A linguistically inappropriate intonational contour can easily lead to misinterpretation and even conflict, showing why instruction such as the teaching intervention in this study is needed.

Although intonation is becoming increasingly prominent in the language classroom, defining exactly what shape the intonation contour should be assigned to a particular sentence is difficult. "As one linguist put it, 'Intonation is predictable (if you are a mind reader)."' (Ladefoged, 2006, p. 118). It is clear that different speakers have different intonation styles. Intonation performs a variety of linguistic functions. As 
mentioned above, intonation may mark grammatical structure and sentence types, may indicate the illocutionary force of speech acts, or may identify speakers with particular sociolinguistic groups (Chun, 2002, p. 77-78). Since there is so much variation in intonation, language teachers must be careful when they teach intonation. Although teaching intonation may be difficult to analyze, there are nevertheless basic, common intonation patterns, such as the ones suggested in Celce-Murcia, et al. (1996), which pronunciation teachers can and should teach their students.

To complicate the teaching of intonation further, American and British applied linguists have established different traditions on how to teach English intonation (Levis, 2005a). The British have emphasized inductively discovering which patterns NSs use and how speakers use intonation to express meaning and attitude. The Americans, on the other hand, have focused on teaching ELLs how to assign intonation patterns, usually based on grammatical structure, and this approach is easier for students to understand than the British approach (Levis, 2005a, p. 357). The textbook that served as the inspiration for this study (Celce-Murcia, et al., 1996) is an example of the American approach.

However, the American system can also be overly simplistic (Levis, 2005a, p. 358). Intonation is part of a complex phonological system influenced by the situation it is used in, the dialect in play, and the position in the discourse, in addition to the age, gender, ethnic group, emotional state, attitude and L1 of the speakers involved ( cf. Chun, 2002, p. 77-78; Couper-Kuhlen, 2007, p. 202, citing Kelly \& Local, 1989). For example, 
sometimes yes/no questions do not have rising intonation. Whether there is a rise or not depends on how certain the speaker is of the answer (Levis, 2005a, p. 359). Because the American approach is simple enough for even lower-level ELLs to understand, I have chosen to teach a variation of it in this study.

Yet another issue with intonation teaching is choosing which dialect to teach. American and British English clearly have markedly different intonation styles, and that is not even to speak of the hundreds of millions of speakers in "expanding circle" countries such as China and India and the styles of intonation which they prefer when speaking English (Markus, 2008). When discussing the pronunciation teaching for English, now the world lingua franca, I agree with the following position,

While political correctness and common sense should prevent us from looking down upon any English variety which deviates from the standard, too great a tolerance of any markedly deviant example of such Englishes seems out of place in the context of language teaching (Markus, 2008, p. 17).

With this reasoning in mind, I have chosen to teach the variety I am most familiar with, the American English of the Pacific Northwest, and to teach the participants in this study the intonation patterns in American English which research has revealed as important for ELLs to know. Since the students in this study were all studying in the Pacific Northwest, it was reasonable to teach them the intonation that is standard for that region.

Another issue that inevitably arises whenever language is taught is that teachers must choose at times whether to be either prescriptive or descriptive. That language 
teachers need to make this choice is especially apparent when they must decide how to deal with language change that is in progress. Uptalk is an example of such a shift. Widespread among young English speakers, uptalk is the use of high rising terminal contours on definite statements where they would not normally occur (Wells, 2006, p. 37). Since uptalk began to appear only around 1980, many older English speakers are not used to hearing it. Rather, some of them find it particularly obnoxious (see Diresta, 2001, for a virulent reaction). With the potential for annoyance in mind, Wells (2006) recommended that anyone born before 1980 not use uptalk and that those born after 1980 should not overuse it (p. 38). When I noticed my participants using uptalk, I pointed out to them that many young people speak that way, but that it is more standard to use a falling intonation contour on definite statements. Nevertheless, I considered uptalk to be a potential contaminating factor in my analysis because it is becoming common in Portland (see Wolff, 2000, for a detailed examination of the use of uptalk in Portland).

Another way to frame the discussion on which variety to teach involves deciding whether to emphasize intelligibility or nativeness (Levis, 2005b, p. 370). Levis suggested that English language teachers should consider where the students will be using English. Having native-like pronunciation is probably more important in "inner circle" countries such as the US compared to "expanding circle" countries such as China (Levis, 2005b). The participants in this study were all students in the IELP, and many of them wanted to continue studying in the US. Therefore, a reasonable but challenging goal for them is to attain more native-like intonation. This thesis was an attempt to help the participants 
become more native-like in their intonation and to test if a particular teaching technique was effective for teaching intonation. The next section considers the relationship of intonation to oral reading, the practice technique used in this study.

\section{3) Oral Reading}

\section{a. The prosody of reading.}

Research on the prosody of reading is relevant to this thesis because the participants' intonation was assessed through listening to them reading written texts aloud. In addition, most of each tutoring session for the teaching intervention was spent on practicing intonation through reading aloud.

When reading a text out loud, how do readers determine the correct prosodic feature to be used? One way that readers do this is through subvocalizing. Whether or not they are aware of it, everyone is familiar with the experience of subvocalizing to some extent when reading. Subvocalizing is the partial articulation of a written text using the speech organs, or in more colloquial terms, to feel out what the words and sentences sound like without fully saying them. When we move our lips as we sound out words, we are subvocalizing, but subvocalizing does not necessarily involve an audible expression of all phonological aspects of the written text. The relationship of subvocalizing to reading aloud is that reading aloud is when readers fully articulate the sounds that a written text represents, but subvocalizing is when readers only partially articulate them. It seems reasonable to assume that both reading aloud and subvocalizing are the result of the same linguistic processes, thereby showing how studies on subvocalizing, such as 
Slowiaczek and Clifton, 1980, are relevant to this study. Subvocalizing is useful for readers in that they can "feel out" the prosody of the written text (Slowiaczek \& Clifton, 1980, p. 573, citing McGuigan, 1970).

The question then is how readers figure out what the prosody of a text is. Readers can figure out how a single word sounds by decoding it letter-by-letter or by recognizing combinations of letters as words they already know how to pronounce. Decoding words is relatively straightforward compared to decoding what the prosody of a text is, but punctuation only imperfectly reflects prosody (Chafe, 1988, p. 397). For example, commas and periods usually represent pauses, but commas are sometimes used for other purposes. Question marks may or may not indicate a final rising tone near the end of the sentence. Punctuation can inconsistently guide the determination of prosody for a written text, but how readers compensate for the inconsistency of punctuation through other means is unclear. Unfortunately, there appears to have been little research on how readers decode a text and determine its prosody. Perhaps if there had been more research on this subject, why the participants in this study chose one intonation pattern over another for a particular sentence may have been clearer.

For several decades, one of the primary means of researching reading has been miscue analysis, a technique which uses oral reading samples to determine how a learner processes a text. A miscue happens when a reader makes an incorrect guess as to how to pronounce a word. By listening to a learner read a text aloud, researchers have made generalizations about how readers extract meaning from a written text. Miscue analysis 
concentrates on how readers decode text by converting it into sound units, syntactic structures, and semantic knowledge (Sachs \& Mahon, 1997, p. 79-80, citing Goodman, 1973). However, when researchers have looked into the conversion of graphemes into spoken sounds, they have concentrated primarily on segmentals. Miscue analysis, like much research on reading in general, has not considered how prosody may be present in texts. Hudson, Lane, and Pullen (2005) emphasized the importance of fluency, especially as practiced in oral reading, as an important reading skill, but much of the research on reading aloud has ignored prosody, one of the main aspects of fluency, even though Hudson, Lane, and Pullen defined fluency in reading as "accurate reading of connected text at a conversational rate with appropriate prosody or expression" (original emphasis retained; p. 703, citing Hudson, Mercer, \& Lane, 2000).

Turning to the topic of intonation in spontaneous speech, ELLs need to use correct prosody in their spontaneous speech because "correct suprasegmental features are essential to prevent pragmatic misunderstandings" (Romero-Trillo \& Llinares-García, 2004, p. 64). Different intonation patterns convey different meanings; therefore, learners who do not have full command of English intonation patterns may miscommunicate by using the incorrect pattern (Romero-Trillo \& Llinares-García, 2004, p. 64, citing Halliday, 1970, \& Tench, 1996). Moreover, ELLs often do not have native-like prosody even for the contours they have acquired. For example, Romero-Trillo and LlinaresGarcía (2004) found that Spanish-speaking college students who read English storybooks to children had not naturally "picked up" native-like prosody when learning English. 
Similarly, Japanese college students learning English had the same problem (Yamato, 2004, p. 67). In the latter study, students read dialogues after having time to prepare, but they often used intonation patterns that did not match up with models from NS speech as they read. The results from both of these studies indicate that ELLs need instruction in native-like prosody, and they also show that having ELLs read aloud is a generally accepted means by which to assess ELLs' intonational accuracy, thereby validating this study's approach to assessing intonation.

Given the generally-accepted idea that most learners of English struggle with prosody when speaking, especially with respect to intonation, stress, and rhythm, most ELLs probably lack the skill of reading (either aloud or subvocally) with correct prosody. In addition to playing a role in increasing a speaker's comprehensibility, prosody may also help learners determine the meaning of a text, as will be shown in the next section on the relationship between oral reading and reading comprehension. To fully understand a text, a reader must understand both how to decode the segmentals and how to discover the prosody of a text.

\section{b. Oral reading and spontaneous speech.}

Another issue that I considered in the research design was how written texts when

read aloud are prosodically different from spoken discourse. Written and spoken language are vastly different. Likewise, read speech and spontaneous speech are intonationally different. 
Research has indicated that speakers use intonation patterns differently when reading compared to speaking. Cruttenden observed that a Glasgow female speaker's oral reading and spoken styles diverged (2007, p. 257). The speaker from Glasgow used a falling tone in read speech where she used a rising tone in conversational speech. There is a difference in English between intonation in a formal style, as in reading aloud, and intonation in an informal style, as in conversation. For example, Lowry (2002) found this kind of difference in the speech of twelve Belfast speakers of English.

Although there are differences between the speech produced during oral reading and the speech produced during conversation, many of these differences are complex and somewhat difficult to categorize, as shown in the following studies on intonational differences. One study using acoustic manipulation involved two speakers of Dutch as readers and thirty-two Dutch-speaking listeners. The study found that the listeners had a difficult time distinguishing read and spoken speaking styles based on prosodic characteristics alone (Laan, 1997). Cruttenden (2007) and Lowry (2002) were able to find differences between oral reading and spontaneous speech in regards to intonation, but Laan (1997) found that the differences were more difficult to discern than Cruttenden and Lowry noted. The different results might be explained by the fact that Laan looked at a different language (Dutch). In addition, Laan relied on technology much more than Cruttenden and Lowry. Laan used software to modify aspects of recorded utterances to try to isolate what made the utterances sound like read or spontaneous (such as changing the pitch to a monotone or making the phoneme duration in a spontaneous utterance 
match that of a read utterance and vice versa). Listeners then classified the utterances as spontaneous or read. Laan could not conclusively isolate a single acoustic feature as marking utterances as spontaneous versus read. Rather, speakers used their perceptions of several different features together to classify utterances. In contrast to Laan's acoustic manipulation and quantitative rating procedure, Lowry used informal observations and Cruttenden used impressionistic judgments of recorded utterances in their analyses.

If language teachers use oral reading in their classes, they must understand that the formal style of oral reading speech may constitute a special register which the students may not transfer to their conversational speech, thereby potentially limiting the gains of pronunciation instruction based on oral reading. The main focus of this study was testing how the students demonstrated intonational accuracy when reading orally. However, because of the issue of transfer between speaking styles, this study also collected data which concerned whether students transfered what they learned while oral reading to their natural speech in conversation,

Based on the differences that Cruttenden (2007) and Lowry (2002) observed in English, it is safe to assume that there are intonational differences between styles in American English. Therefore, this study and others that look at prosody by analyzing samples of oral reading speech must take into account intonational differences between speech and text. Findings from research that uses oral reading data need to be applied carefully if they are generalized to casual conversation. The question is if improvements in learners' speech gained through oral reading practice transfer to other speech contexts. 
In order to control for context, this study focused on whether ELLs can learn to use intonation patterns in oral reading, although I also collected some naturalistic data to see if there were intonational differences between the participants' read and spontaneous speech. Testing if the knowledge of these intonation patterns transfered to other contexts was part of the design of this study, although given the very limited amount of seminaturalistic data used in this study, future research is surely needed. In the next sections, I turn to the question of how pronunciation, and intonation in particular, may be taught through oral reading so as to show why I chose to use oral reading in the teaching intervention for this study.

\section{4) Teaching Pronunciation through Oral Reading}

It is common pedagogical practice to first present the rules for a particular linguistic pattern and then practice those rules through an activity. In this study, explicit pronunciation instruction (focusing on intonation) was initially presented, and oral reading was the primary practice activity. Oral reading takes away the cognitive burden of generating language by providing students with texts to read. One model for teaching pronunciation suggests that students should first train through dependent practice, such as repeating after the teacher, then through guided practice, such as oral reading, and finally through extemporaneous practice, such as naturalistic conversation (Morley, 1994, p. 8485). As a form of guided practice, oral reading allows students to pay attention to pronunciation rather than vocabulary and morphosyntax. Because students do not need to construct sentences themselves, their cognitive load is lessened, thereby allowing them to 
pay close attention to pronunciation. After spending some time training in this form of guided practice, students can progress on to less controlled forms of practice such as extemporaneous conversation. However, because the teaching intervention in this study lasted only five weeks, the participants had time to train only through guided practice.

\section{5) Intonation Contours}

I chose the set of intonation patterns listed in Table 1 to use in this study because instruction in these patterns makes a significant difference in the comprehensibility of an ELL's speech (Celce-Murcia, et al., 1996, p. 201-208). The teaching intervention component of this study concentrated on these four contours (see the methodology subsection on the teaching intervention and Appendix $\mathrm{C}$ [a description of a typical tutoring session] for details on the teaching intervention).

Table 1

\section{Intonation Contours}

\begin{tabular}{|l|l|l|}
\hline Contour & Pitch & Example \\
\hline Definite statements & $\begin{array}{l}\text { The intonational phrase ends } \\
\text { on a low boundary tone. }\end{array}$ & I'm on my way to Portland. \\
\hline Yes/no questions & $\begin{array}{l}\text { The intonational phrase ends } \\
\text { on a high boundary tone. }\end{array}$ & Do you know the way to Portland? \\
\hline wh-questions & $\begin{array}{l}\text { The intonational phrase ends } \\
\text { on a low boundary tone. }\end{array}$ & Which way is it to Portland? \\
\hline Tag questions & $\begin{array}{l}\text { The intonational phrase ends } \\
\text { on a high boundary tone. }\end{array}$ & You're going to Portland, aren't you? \\
\hline
\end{tabular}

The four intonation contours listed in Table 1 are defined by the syntax of the sentences with which they are associated. Definite statements tend to have final falling intonation (that is, a low boundary tone), and so do wh-questions. Yes/no questions and 
tag questions usually have a final rising pitch contour (that is, a high boundary tone). The teaching intervention used in this study focused on teaching the default contours listed here. For example, although tag questions often have a rising pitch contour, speakers may deviate from this default setting for the intonation pattern and use a fall instead. During the teaching intervention, I informed the participants that the sentence types listed in Table 1 take the intonation patterns explained above by default, but sometimes speakers may use other patterns to accomplish particular discourse functions. Tag questions, for instance, may be said with a fall, resulting in the perception that the speaker is asserting the truth of the definite statement to which the tag question is attached. By teaching the default contours, I attempted to instill in the participants an awareness of English intonation, not to teach them to account for every possible variation in intonation in English, which would be impossible. Therefore, I chose to concentrate on several default patterns which are salient enough to be explained to students with relative ease.

These patterns are important for communicating meaning in discourse (CelceMurcia, et al., 1996, p. 200, citing Gumperz \& Kaltman, 1980, p. 62, \& Chun, 1988, p. 81; Gumperz, 1982) and thus useful for ELLs to know. In addition, these contours are all defined by a particular shape to the rise and fall of the pitch pattern. The intonation contours associated with the sentence types listed in Table 1 also frequently appear in English, another reason to teach them to ELLs. The question then arises as to how best teach these patterns to ELLs, and this study specifically tested how oral reading may be 
used to teach East Asians. The next section considers the particular difficulties that East Asian ELLs are likely to have when learning English intonation.

\section{6) East Asian Learners and Intonation}

Anyone who has studied a foreign language, especially one from an entirely different language family, knows the difficulty of acquiring a native-like accent in the L2. Non-native-like prosody, including intonation, often contributes heavily to an ELL's foreign accent (Anderson-Hsieh, Johnson, \& Koehler, 1992). In this study, the participants were all from East Asia, with none of their L1s being even remotely related to English. Although it is clear that many ELLs fail to sound like NSs, there are exceptions. For example, Bongaerts, van Summeren, Planken, \& Schils (1997) found that some highly proficient Dutch learners of English with strong motivation to sound nativelike successfully learned how to do so (p. 462). In that study, British English NS judged the accents of Dutch ELLs, and the researchers found a correlation between high motivation and native-like accent. However, English is much more closely related to Dutch than it is to Korean, Japanese, Vietnamese, or Chinese, the L1s of the participants in this study. Although some speakers of East Asian languages attain native-like pronunciation and even intonation if they spend long enough in an English-speaking environment, many East Asian ELLs never attain native-like pronunciation including intonation (see Wennerstrom, 2001, and Burleson, 2007, for evidence on Japanese learners). 
Transfer theory is foundational to understanding the second language acquisition process. Negative transfer from L1 to L2 explains much of the difficulty East Asian ELLs have in sounding native-like. ELLs transfer parts of their L1's phonological system into their speech in the L2, resulting in an interlanguage with a pronunciation that combines elements of both the L1 and L2. In terms of intonation, negative transfer occurs when East Asian ELLs use elements of their L1's intonational system when speaking English, and this transfer accounts for some aspects of the strong accent which some East Asian ELLs have. In order to analyze the issue of transfer in detail, I present the intonation systems of the participants, starting with Mandarin Chinese and continuing with Cantonese, Japanese, Korean, and Vietnamese. Understanding the prosodic systems of the L1s may help to explain both the difficulties the participants faced in learning English intonation and the success they attained as determined by the pre- and post-tests used in this study. Of the eight participants in this study, five spoke Mandarin Chinese, one of which also spoke Cantonese. The other three participants spoke Japanese, Korean, and Vietnamese, respectively. In the following sub-sections, I also describe elements of prosody other than intonation because other aspects of prosody such as stress and rhythm/timing influence the intonation of utterances, especially in terms of where speakers place the boundary tones. In each section, I describe the stress and rhythm of the L1, and then focus on the L1's intonational system and potential transference that may occur from the L1 into English. 


\section{a. Intonation in Mandarin Chinese}

Mandarin is more syllable-timed than English, a basically stress-timed language. Standard Mandarin based on the Beijing dialect gives a full beat to some syllables, but a half-beat to reduced syllables, which are those with a "neutral" tone (more on tones in the next paragraph). However, Taiwan Mandarin and other varieties of Mandarin from southern China make all syllables have a full beat, with the exception of a few grammatical particles (Norman, 1988, p. 148-149). Chinese ELLs, especially those from southern China and Taiwan, often make the length of each syllable somewhat uniform in conformity with the rhythm of their L1. (Of the five Chinese-speaking participants, two were from Taiwan and one was from southern China. The other two Chinese speakers were from northern China.) Since stressed syllables in English are longer than unstressed ones, Mandarin speakers often do not sound native-like in English because of the rhythm of their speech alone (see the intonation theory section of the literature review for a description of rhythm, accent, and stress in English).

In addition, Mandarin Chinese, unlike American English, has lexical tone, meaning that each syllable has a tone assigned to it. There are four main tones and one "neutral" (a.k.a. "light" or "zero") tone whose pitch value is determined by the preceding main tone. Lexical tones and intonation co-exist in Mandarin Chinese (Shen, 1990). Intonation seems to be laid on top of the lexical tones, but compared to an "intonation language" like English, there are far fewer possible intonation patterns. In addition, Mandarin intonation can raise or lower the tones in a sentence. For example, Shen (1990) 
showed that speakers raised the level of interrogative sentences to a relatively higher pitch compared to non-interrogative sentences. Unlike in English, "pitch scale rather than pitch shape characterizes intonation patterns" in Mandarin (Shen, 1990, p. 79). Therefore, when speakers of Mandarin learn English, they must adapt to an intonation system with many more possible variations because, in English, the shape of an intonational contour is more important than the overall height of its pitch. When Chinese ELLs begin learning English, they start out with a much more limited set of contours than an English NS, and therefore they have a large number of contours to acquire in English.

The difficulties of learning English intonation for Chinese students have been analyzed in several studies, e.g., Meng and Wang (2009) and Rui (2007). In the former, the boundary tones in Chinese students' speech when reading an English text were compared to the boundary tones in the utterances of native British English speakers. The Chinese students' boundary tones were native-like only when they read short imperatives, one out of the seven sentence types tested overall. Rui (2007) compared the spontaneous and oral reading speech of English-major undergraduates in China to that of British NSs and found that the Chinese ELLs often exhibited non-native-like intonation patterns. These two studies indicate why I chose to address the need of Chinese ELLs to acquire native-like boundary tones in this thesis. Mandarin speakers face the formidable task of learning the complex English intonation system, and they also must adapt to the stresstiming of English. Thus, there would be great benefit in finding a successful technique for overcoming these challenges. 


\section{b. Intonation in Cantonese}

Of the five Chinese participants in this study, one female (Water [a pseudonym]) spoke Cantonese natively in addition to being fluent in Mandarin. Like Mandarin, Cantonese is syllable-timed (Flynn, 2003, p. 46). Cantonese is also similar to Mandarin in that it is tonal, but it has more tones than Mandarin. According to Flynn (2003), Cantonese has between six and eleven tones depending on how they are counted (p. 5), eg. Ramsey (1987) described nine basic tones in Cantonese (p. 103). Cantonese has a system of tone sandhi, that is, the tones influence each other when in contact. As the tones modify each other, they thereby also modify the intonation contour of the utterance (Flynn, 2003, p. 125).

These facts characterizing Cantonese prosody suggest that Cantonese-speaking ELLs may have difficulties sounding native-like. One factor is that, when learning English, Cantonese speakers may transfer their comparatively smaller intonational repertoire from their L1, resulting in them underusing the English intonation system to convey meaning. Flynn (2003) offered the following explanation as to why Cantonese speakers do not use utterance level intonation in the way that English speakers do, "There is not much freedom left for changing pitch movement on top of lexical tone orientation in Cantonese. This indicates that intonation manipulation in Cantonese cannot be expected to be the same as in a non-tone language like English" (p. 65). Another issue for Cantonese ELLs is that they tend to sound "choppy" when speaking English. By “choppiness," I am referring to timing syllables at approximately equal intervals and 
cutting some syllables off with unreleased, often glottalized, final consonants. There are at least three causes for this choppy quality: the syllable-timed nature of their L1, the way in which final consonants are pronounced in Cantonese, and the tendency in Cantonese to use staccato rhythm. First, as explained above, ELLs who speak syllable-timed languages have difficulty adapting to the stress-timed nature of English. Second, three of the Cantonese tones end abruptly in voiceless stops (Ramsey, 1987, p. 103). Third, Cantonese speakers sometimes chop syllables for emphasis, resulting in staccato rhythm (Flynn, 2003, p. 77). Staccato rhythm results from when speakers force air out of the lungs more quickly than would be normal and then abruptly cut off the flow of breath at the end of the syllable (p. 77). A third problem for Cantonese speakers learning English is that focus is handled differently. In Cantonese, focus is accomplished primarily through lengthening the syllable, and pitch exaggeration and loudness also play a role (Flynn, 2003, p. 125). This way of focusing is in contrast to English in which pitch is the most important feature, and length and loudness are secondary (Bolinger, 1986).

\section{c. Intonation in Japanese}

Unlike English and Chinese, Japanese is mora-timed. Researchers on Japanese, instead of thinking of phonemes as being structured into syllables, use morae (singular: mora) to group phonemes (Tsujimura, 1996, p. 64-65). A mora is a timing unit that can consist of a vowel, a consonant and a vowel, or a final nasal. Long vowels thus consist of two morae. Each mora takes approximately the same amount of time to say. Furthermore, Japanese is the classic example of a pitch-accent language where speakers accent some 
morae with pitch drops (Abe, 1998, p. 361). This distinction by pitch results in minimal pairs such as HAshi "chopsticks" and haSHI "bridge." Although the Japanese pitchaccent system uses pitch to distinguish words, it does not have a defined pitch contour or tone for individual morae. Instead, pitch accent is syntagmatic, that is, it is meaningful only when a speaker pronounces a combination of pitch-accented and unaccented morae. Either a syllable has a pitch accent or it is pitch accent-less in Japanese. This feature of pitch accent is in contrast to lexical tone where single syllables in isolation can be distinguished on the basis of their tone alone. The mora on which the pitch accent falls on is not predictable, and thus pitch accent is lexically determined. (English has a stressbased system where the assignment of stress is lexical, syntactic, and phonological.) Therefore, Japanese uses pitch to distinguish words, although not in the same way as English. Japanese ELLs then are likely to have difficulty learning how to use pitch in English in a native-like way.

In English, two purposes of intonation are to express attitudes and manage discourse. In Japanese, particles often serve the same functions (see Lammers, 2005 for an accessible introduction to the Japanese particle system). Because of the role that particles fill in Japanese, intonation may be relatively less important in Japanese than in English. However, sometimes intonation can play an important role in marking sentence type in Japanese. For example, speakers use the sentence final particle $-k a$ to change statements into questions. In the Tokyo dialect, $-k a$ may be dropped if the pitch rises at the end of the utterance (i.e. if there is a high final boundary tone; Abe, 1998, p. 367). In 
other dialects, intonation may function differently. The single Japanese participant in this study claimed to speak the Kansai dialect, which uses a level tone at the end of a question rather than either a rising or falling tone (Abe, 1998, p. 369, citing Fujiwara, 1964). Overall, Japanese does not seem to employ as wide a range of intonation contours as English, meaning that Japanese ELLs likely will have an insufficient intonational repertoire for use in English.

\section{d. Intonation in Korean}

Korean is a syllable-timed language like Chinese. Unlike in English, placement of stress does not distinguish words in Korean (Gim, 2007, p. 91). Similarly to English (and the following may be present to some extent in all languages [Bolinger, 1978]), Korean intonation uses a final falling tone for declaratives and a final rising tone for interrogatives (p. 92-94). One parallel between English and Korean intonation is that declaratives may be changed to interrogatives without changing the morphosyntax of the utterance simply by having a rising intonation at the end (p. 95). Although intonation in Korean is in some ways similar to English, Korean ELLs often sound "flat" when speaking English because their pitch remains relatively constant, thereby not marking stressed syllables with a higher pitch (see Yavaş, 2006, p. 195, for an explanation of common pronunciation problems Korean ELLs have).

\section{e. Intonation in Vietnamese}

Vietnamese is a syllable-timed tonal language like Mandarin; the standard dialect of Hanoi distinguishes six tones. Thompson (1987) claimed that Vietnamese has three 
levels of stress distinguished by loudness: heavy, medium, and weak (p. 17). New information or the focus of the utterance receives the strongest stress, and old information the weakest. Similar to English, a low boundary tone at the end of the utterance signals speaker certainty, and a high boundary tone uncertainty (often marking an interrogative). Even though Vietnamese is tonal, the tone for the word at the end of the utterance is marked with a low boundary tone. It also appears that, as in Chinese, the intonation is laid over the top of the lexical tones in an utterance, that is, the intonation can shift all of the tones in the utterance up or down. In Vietnamese, speakers also use "spread tone," which is when the tone covers a wider part of the speaker's pitch range than is usual, in order to express emotion or even indifference.

In my experience working as an ESL teaching assistant at Portland Community College, Vietnamese ELLs often sound "choppy" when speaking English. They stress each syllable equally rather than only making stressed syllables louder, longer, and at a higher pitch, a feature attributable to the syllable-timed nature of Vietnamese. Because the syllable is perceived as the basic unit of meaning in Vietnamese, Vietnamese standard orthography even groups letters by syllable rather than by word, contributing further to the highly analytic nature of Vietnamese (Dung, Huong, \& Boulakia, 1998, p. 395-396). In addition, Vietnamese has two tones which end in glottal stops (Ngo, 2003). In my experience, Vietnamese ELLs often use glottal stops in English where NSs would not, contributing further to the choppiness of their speech. Since Vietnamese has tones and a range of particles to indicate emotion and attitude, it appears that intonation in 
Vietnamese is less important for meaning than in English (Dung, Huong, \& Boulakia, 1998, p. 399, citing Gordina \& Bystrov, 1984, and Pechkovskij, 1959). Therefore, like speakers of Chinese and Japanese, Vietnamese ELLs are likely to use only a subset of the intonation contours in English that are available.

Now that I have described the intonation systems of participants first languages, I will look at how affect and motivation of East Asian ELLs and the teaching environment in East Asia has created the need for more pronunciation instruction for this group of students.

\section{7) Affect, Motivation, and English Language Teaching in East Asia}

Motivation is key when learning a foreign language. In a review of various studies, Gass and Selinker (2008) wrote that there is no doubt that high motivation increases the chance that an ELL will succeed in learning English (p. 426). Motivation can come from a variety of outside sources, including parents, friends, government, or the culture in general. Other possible motivations are internal, include a desire to learn, a need for a good job, or a wish to enter fully into another culture through its language. If these motivations are strong, a learner is more likely to become fluent in the L2. However, every learner has a different set of motivations.

Several of the ELLs in this study were Chinese, and all of them came from countries heavily influenced by Chinese culture. Since the largest group of ELLs in this study was Chinese, Chen, Warden, and Chang's (2005) explanation of how motivation is constructed in Chinese society is apt. (For the purposes of this discussion, ELLs from 
both mainland China and the Republic of China [Taiwan] are considered Chinese.) Chen et al. (2005) proposed a model for the motivation to learn English in Chinese society: Chinese parents pressure their children to do well on tests and excel overall in school. When the students finish school, society expects them to find a good job through which they will be able to support their parents as they age. Since English is perceived as the international language of advancement throughout the Chinese-speaking world, parents expect their children to learn English well, and they expect them to show that they have done so through obtaining high scores on standardized tests.

An anecdote reveals that, although strong external motivation often pushes Chinese ELLs to achieve high scores on tests, learners often spend their time memorizing word lists and grammatical rules. I myself tutored an undergraduate student at Portland State who was preparing to take the Graduate Record Exam (GRE). He explained to me that he was studying a word list of tens of thousands of vocabulary items and reading a book on how to memorize them all in about a month. Such learning strategies are common in Chinese society, hence the proliferation of "cram schools" or buxiban ('extra review classes'). Many students take classes in cram schools after the public school day has ended (Chen et al., 2008, p. 625).

I spent two years teaching English at two different cram schools in Kaohsiung in southern Taiwan before entering the MA TESOL program at Portland State. Based on my experiences and numerous conversations with other expatriate English teachers, rote memorization of grammar and vocabulary is the emphasis of much English education in 
Taiwan. The public schools in the Chinese-speaking world generally instruct students extensively in grammar and reading, and sometimes also listening, but usually neglect writing and especially speaking (cf. Rui, 2007). Pronunciation in particular is rarely taught. In sum, although learning English is highly valued in Chinese society, few Chinese ELLs have the chance to work on speaking when they are learning English in their home culture. The fact that eight Chinese students (out of a total of 31 potential participants) expressed interest in receiving intonation tutoring indicates that Chinese students are aware that their speaking skills are often deficient and want to improve their pronunciation. This study addresses the desire of these students to have better pronunciation. Although Chinese ELLs may not be aware that their intonation in particular is not native-like, the previous sections on the intonation systems of Mandarin and Cantonese show that there are many differences, and thus there is a need for intonation instruction among Chinese ELLs.

Although I am not personally familiar with English language teaching (ELT) in Japan, Vietnam, or Korea, other language teachers have noticed some similarities with the Chinese situation. A major commonality is that ELT pedagogy across East Asia emphasizes reading and grammar over writing, listening, and speaking. Pronunciation is rarely taught explicitly. These observations are based on the summary of common ELT pedagogical practice in Matsuya (2003) for Japan and Canh and Barnard (2009) for East Asia in general, focusing on Vietnam in particular. Canh and Barnard (2009) pointed out that, although communicative language teaching has been actively promoted by 
governments across East Asia, English language teachers are often ill-prepared or unwilling to adopt such an approach. Given that all participants in this study clearly wanted to study English pronunciation (otherwise they would not have signed up as potential participants in the first place), some ELLs see a need for pronunciation instruction and are motivated to study hard to improve their spoken English.

In addition to motivation, affect can also greatly change how well ELLs learn a foreign language. In this study, I investigated the effect of the teaching method on both the participants' affect and their motivation through entrance and exit interviews. Krashen's model of the affective filter as serving to either increase or inhibit language acquisition is well known (see Gass \& Selinker, 2008, p. 401-402, on Krashen, 1985). If ELLs enjoy a particular teaching technique, then they are likely to learn more. If they do not enjoy it, then they are likely to learn less. In the case of this study, if the participants enjoyed the oral reading practice, that indicates that teachers may want to use this kind of practice to teach intonation.

The motivations that the participants brought to the teaching sessions surely influenced how much and how well they learned about English intonation. In addition, their affective reaction to the teaching method in terms of enjoyment, frustration, or indifference likely had an effect. Therefore, I have made efforts to account for these two variables, affect and motivation, through conducting the initial questionnaires and exit interviews. 


\section{Methodology}

\section{1) Finding and Selecting Participants}

To find participants, I contacted teachers in the Intensive English Language Program (IELP) at Portland State University. Many international students study in the IELP before enrolling in regular classes at Portland State, but some also study in the IELP to improve their English for other reasons, such as work or travel (Portland State University, 2010, paragraph 3). When I emailed the teachers, I explained to them that I was researching intonation and wanted to tutor IELP students individually on intonation. I asked them to recommend students who had difficulties with English intonation and who might be receptive to participating in this study. I explained that, in addition to giving the students free intonation instruction, I would also tutor them in whatever other English skills they wished to work on. This additional instruction would then serve, perhaps, as some compensation for the time the students spent participating in this study. Several teachers responded favorably and allowed me to go to three IELP classes, give a short presentation of what the study was about, and ask students to sign up for tutoring. One teacher put me in direct contact with several students who were interested (in lieu of having me come to her class).

I originally had wanted to have only male, Chinese, intermediate-level participants. I hoped that restricting myself to teaching male students would help control for gender-determined intonational differences, as well as limit problems in cross-gender interactions. In order to control for first language, I sought learners who spoke Mandarin 
Chinese. I also sought Chinese students because of my familiarity with Standard Mandarin and Chinese culture. Furthermore, I wanted to recruit Chinese students who spoke the same Chinese language (called "dialects" by the Chinese government). I tried to restrict myself to students at approximately the same English proficiency level (as determined by the level of classes they are taking in the IELP), preferably intermediatelevel students. Choosing intermediate-level students rather than low-level was also important because that allowed us to have an easier time communicating exclusively in English. Overall, I sought participants who were as similar as possible in terms of L1 background, gender, and English level in order to have a homogeneous group of participants and thereby eliminate as many extraneous variables as possible. However, I was forced to select a more heterogeneous group of participants than I wanted, as explained below.

With the help of the IELP teachers, I obtained a list of 31 students from which to select the participants. Although the participants were to be ideally to be intermediatelevel (defined as IELP levels 2 through 4), male speakers of Mandarin Chinese, I could see from the list that I did not have enough participants who fulfilled all of those criteria. Since I wanted to have complete data for three to five participants, I contacted 14 students and asked them to participate in the study in order to account for the high rate of attrition that I expected. (I knew from experience as an ESL tutor that students often miss sessions.) 
I chose the initial participants by first selecting all Chinese-speaking students (there were eight), and then selecting all males from elsewhere in East Asia: one Japanese, three Koreans, and two Vietnamese. Of those 14, 12 responded to my email requests and set up initial sessions with me. I met with 11 of those students, and I conducted initial sessions with each one (one student did not show up for the initial session). Three of these students (two females, one male) were from mainland China, three from Taiwan (two females, one male), two from Korea (both males), two from Vietnam (both males), and one from Japan (a male). Four females and seven males made up the initial participant group. I eventually dropped two of the students because they were not able to come to some of the sessions and rescheduling proved impractical. A third completed the tutoring sessions, but it was not possible to schedule the post-test and exit interview with him. At the end of the teaching intervention period, I had eight participants (three females, five males) whom I had tutored for five sessions each, resulting in approximately 150 minutes of individual intonation instruction for each student.

I assigned each participant a pseudonym, with the exception of Water, who chose her own. General information for the eight participants who fully participated in the study is summarized in Table 2. 
Table 2

Participant Pseudonyms and Backgrounds

\begin{tabular}{|l|l|l|l|l|}
\hline Pseudonym & Water & Ray & Betty & Dan \\
\hline Location of Origin & Mainland China & Mainland China & Mainland China & Taiwan \\
\hline Pseudonym & Simon & Long & Shinjiro & Lulu \\
\hline Location of Origin & Korea & Vietnam & Japan & Taiwan \\
\hline
\end{tabular}

\section{2) Participant Characteristics}

In terms of career and future plans, the participants came from a variety of academic disciplines, including interior design, business management, accounting, international trade, transportation management, and political science. Four of the participants were interested in or had completed degrees in fields related to business or finance. Six of them expected to use English at work in the future, and four expected to continue studying in the US after completing IELP courses and therefore needed better English skills for their future studies. Using English to improve their career prospects was clearly a motivation for most of the participants to improve their pronunciation.

As mentioned before, all of the participants were taking IELP classes at the time of the study. Long, a Vietnamese male, was taking only an IELP pronunciation course in addition to political science classes, but the other participants were enrolled in other IELP classes as well. The IELP levels of the students are summarized in Table 3. One student was in level two, four in level three, and two in level five. 
Table 3

Levels of the IELP Courses the Participants were Enrolled in

\begin{tabular}{|l|l|l|l|l|}
\hline Pseudonym & Water & Ray & Betty & Dan \\
\hline IELP Course Level & 2 & 3 & 5 & 3 \\
\hline Pseudonym & Simon & Long & Shinjiro & Lulu \\
\hline IELP Course Level & 5 & N/A & 3 & 3 \\
\hline
\end{tabular}

In the initial interviews, all of the participants reported that they had been in the US for only a relatively short time, ranging between two weeks and four months. Six of the participants had previously visited the US or other English-speaking countries for a few weeks or months, but only one had previously lived in an English-speaking country. (Long had spent 20 months in Australia obtaining a Master's degree.)

In terms of English study, all the participants reported that they had been studying English for at least seven years, with Water having spent the most time: about 16 years. All of them had studied reading and writing much more than speaking. Three of them had practiced listening to English extensively, although the others had not. Shinjiro and Simon had focused on speaking in at least one of their English classes before. (Both Shinjiro and Simon had received pronunciation tutoring in the IELP and had been taught speaking in their home countries.) The other participants claimed to have had little chance to practice speaking English in school. Two of the participants had received tutoring in the IELP for their pronunciation, and one had help from his American host father with pronunciation, but the other six participants had not been taught explicitly pronunciation prior to this study. Of those two who had studied pronunciation before, two 
had also practiced mimicking the intonation of NSs, but it appears that none of the participants had been explicitly taught intonation before. With two exceptions, all the participants were most familiar with the American English accent. The other two were more accustomed to British and Australian English.

The participants cited reasons for studying English pronunciation such as wanting to communicate naturally with NSs and feeling that their pronunciation of English was simply "bad." Several of them referenced their perceived need to improve the speaking skills.

Based on the situations the participants described in which they were misunderstood by Americans and the areas in which they thought their pronunciation needed improvement, the participants did not seem to know at the start of the study if and how their intonation differed from that of NSs. The one exception was Simon, who pointed out that, when Koreans speak English, they often sound monotonic. This lack of awareness of intonational accuracy demonstrates that the participants had not received even intonation awareness instruction, and providing them with that was one of the goals of this study.

From these initial interview data, it is clear that the participants had not received much intonation instruction before. Most of them also stated that their speaking skills were not as good as they wanted them to be. Shinjiro even stated, "My pronunciation is bad." Clearly, the participants were motivated to study English pronunciation. Furthermore, all of them reported that they would need good English skills for work or 
education in the future. In sum, this study provided the participants with instruction that was in line with their motivations and their need for better English skills in the future.

\section{3) Data Collection}

\section{a. Overview of procedures.}

This study began with a pre-test and questionnaire, followed by a five-week teaching intervention, and ended with a post-test and interview. At the initial tutoring session, I obtained the students' consent to participate in the study, administered the pretest and the questionnaire, and gave the first lesson of the teaching intervention if there was time (see Appendix $\mathrm{C}$ for a description of a typical tutoring session). I explained to the students the benefits and risks of participating in this study and asked their permission to record them during the tutoring session, telling them that I would record all of the first session so as to obtain a sample of their speech. I explained to them that I would assign them a pseudonym so that they would remain anonymous, in accordance with the conditions set by the Human Subjects Committee.

When the participants had agreed to participate and allow me to collect data, I administered the pre-test and questionnaire. For the next five weeks, I instructed the students by presenting the intonation patterns and then practicing those patterns with oral reading. At the end of the tutoring sessions, I administered the post-test. Including the initial meeting, the five tutoring sessions, and the post-test meeting, I met with each participant at least seven times. Finally, a colleague interviewed the students to assess 
their feelings about the instruction as well as their awareness of their own intonation patterns.

\section{b. Pre-test.}

The pre-test had two components, both of which were recorded on a MacBook using the built-in microphone. The first part consisted of students reading texts; the second, focusing on natural conversation, was conducted concurrently with and immediately after the initial session questionnaire. For the oral reading component, I asked the student to read aloud two short stories while being recorded. One story was "Bliss" by Anton Chekhov, translated by Marian Fell (Chekhov, 2010), the other "Hills Like White Elephants" by Ernest Hemingway (Hemingway, 2007). I selected and modified the two stories to keep the syntax and vocabulary simple and appropriate to their proficiency level, and to have each passage contain the complete set of intonation contours used in this study (see Appendix D for the text of "Bliss" showing the modifications). Both the vocabulary level and syntactic complexity were controlled so that the reading was neither extremely easy nor extremely difficult. I kept the lexical and syntactic complexity of the passages low because students at the intermediate level are only able to read passages commensurate with their proficiency level. In retrospect, "Hills Like White Elephants" proved to be too long, taking one student almost 18 minutes to read aloud. "Bliss" took the same student about 10 minutes to read.

The following is a list of the contours from "Hills Like White Elephants" which I used for the oral reading component of the pre-test. One pronunciation textbook 
suggested using this story by Ernest Hemingway to practice intonation while reading aloud (Celce-Murcia, et al., 1996, p. 215-217); this was a good suggestion because this story is ideal for testing intonational accuracy since most of the text is dialogue. Here are examples of each contour from the story:

definite statements: "The girl was looking off at the line of hills." yes/no questions: "Could we try it?"

wh-questions "What did you say?"

tag questions "That's all we do, isn't it [...]" (Hemingway, 2007).

The passages were short stories chosen because of their large amounts of dialogue, since that text type provided a variety of intonation contours. However, I found it necessary to change some sentences in each story to increase the number of contours for particular types, as mentioned above. Both stories contained numerous definite statements, but I had to add most of the tag questions. For example, "Bliss" contained three yes/no questions, seven wh-questions, and no tag questions, but my modifications changed the count for each of these sentence types to six. The counts for each sentence type are listed in Table 4 and 5: 
Table 4

Sentence type counts for "Hills Like White Elephants"

\begin{tabular}{|l|c|c|}
\hline Sentence Type & Number in Unmodified Text & Number in Modified Text \\
\hline Definite statements & over 10 & over 10 \\
\hline Yes/no questions & 17 & 16 \\
\hline Wh-questions & 8 & 7 \\
\hline Tag questions & 1 & 5 \\
\hline
\end{tabular}

Table 5

Sentence type counts for "Bliss"

\begin{tabular}{|l|c|c|}
\hline Sentence Type & Number in Unmodified Text & Number in Modified Text \\
\hline Definite statements & over 10 & over 10 \\
\hline Yes/no questions & 3 & 6 \\
\hline Wh-questions & 7 & 6 \\
\hline Tag questions & 0 & 6 \\
\hline
\end{tabular}

\section{c. Questionnaire.}

In the first tutoring session after I had administered the oral reading component of the pre-test, I gathered information about the student's language learning experiences, L1 background, etc., using a modified version of the questionnaire provided in CelceMurcia, et al. (1996, p. 396-7), as shown in Appendix A. These data were used to describe the participants in the previous sub-section titled "Participant Characteristics." I also planned to use the data from the questionnaire to explain differences in the 
quantitative results if some participants improved in their intonational accuracy but others did not. For example, one of the questions asked whether or not the student had previously been taught English intonation. Such previous experiences could skew the results.

In addition to testing the students' intonational accuracy through oral reading, I attempted to assess their intonational accuracy as they responded to the questionnaire. Since the questionnaire was recorded, I used the responses to assess their control of English intonation during relatively naturalistic conversation. I referred to the questionnaire questions as little as possible, thereby making the interview seem more like a natural conversation. When I gave them the initial sentence questionnaire, most of the responses were expected to be definite statements. The final question on the questionnaire was used to elicit questions of different types.

The first purpose of eliciting the different sentence types in conversation was to see if there was a difference between the students' oral reading intonation and their intonation in more natural conversation (see Cruttenden, 2007, for a discussion of “intonational divergence"). The second purpose was to see if the students' intonational accuracy improved between the pre- and post-tests. If the students' intonational accuracy improved, then what they had learned while reading aloud may have been transferred to their speech in natural conversation. 


\section{d. Teaching intervention.}

After administering the pre-test (which consisted of the oral reading test and the questionnaire with eliciting statements), I tutored the student in how NSs (native speakers) of English use the intonation contours shown in Table 1. The tutoring sessions lasted for about an hour, with one session per week for seven weeks. The initial session was used for the pre-test and questionnaire, the middle five sessions for the teaching intervention itself, and the last session for the exit test.

In exchange for their help with my research, I used half of the tutoring session to help the students work on whatever English skills they wanted to improve. If they asked for further help with pronunciation during the half of the tutoring session that did not focus on oral reading and intonation, I provided that help, noting the nature of the assistance that I provided since it could be a contaminating factor. All but one participant (Lulu) received instruction from me in the second half on the segmental aspects of pronunciation, which touched on the articulation of vowels and consonants, linking (for

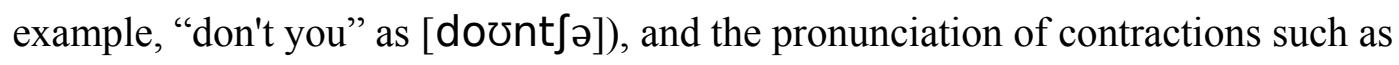
"we'll." The non-pronunciation instruction that the participants requested me to provide included revising papers, explaining grammar points, and conversation practice. Giving the students control over this part of the tutoring may have increased their motivation to complete the entire tutoring sequence. Unexpectedly, four of the participants requested at least once to forgo the second half of one of the tutoring sessions. 
The teaching objectives of the tutoring sessions were to have students develop more native-like intonation patterns and to increase their awareness of their own pronunciation. I used techniques for teaching intonation suggested in Celce-Murcia, et al. (1996, p. 175-220), particularly the suggestion for reading aloud "Hills Like White Elephants" by Hemingway (p. 215-216). During the tutoring, I illustrated the shape of the intonation contours by first drawing the contours over example sentences (see Figure 1). Visualizations of pitch have been shown to be effective for teaching intonation (Seferoglu, 2005). Next, I modeled those intonation contours for the students. I had the students repeat after me as I read the example sentences. Once the students were comfortable with the pattern, I had them practice determining the correct intonation contour for other sentences. The teaching sessions concentrated on the four basic intonation patterns detailed in the Intonation Contours section of the literature review. However, when the students encountered a new contour that we had not covered as they read aloud, I explained those contours to them. (I only assessed those four intonation patterns for the quantitative part of this thesis, but the teaching intervention also included instruction in other patterns.) 
Figure 1. Example intonation contour drawing for a declarative sentence.

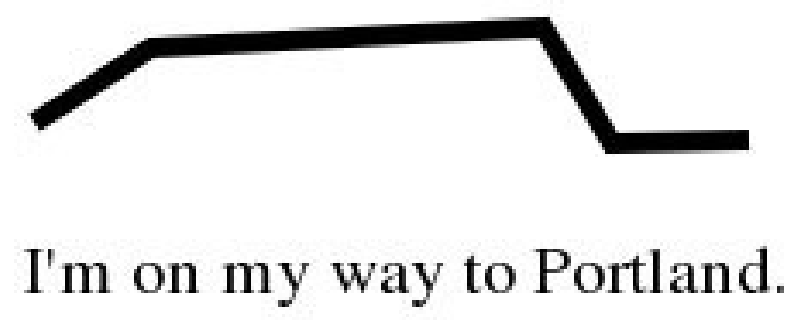

After this initial presentation and practice of the contours, the students practiced reading aloud. The texts read were short stories or excerpts from plays. Because of the range of their English ability levels, each session was tailored to the student's level. In particular, although the two initial texts ("Hills Like White Elephants" by Ernest Hemingway and "Bliss" by Anton Chekhov) that we read and analyzed for intonation patterns were identical, the differing ability levels of the students caused me to select different texts for oral reading thereafter. The level five students read "Ylla," a short story from the Martian Chronicles by Ray Bradbury, and the level two and three students (except for a Chinese student, Ray) read "The Collection" by Harold Pinter. I did not modify either of these texts before the students read them. I initially tested "Ylla" on Water, a level two student and Shinjiro, a level three student, but both of them complained that the text was too difficult in terms of vocabulary, so I found "the Collection" for the lower level students to read. After finishing the practice with the two pre-test stories, both "Ylla" and "the Collection" proved to be so long that I did not have time to have the students practice with other stories or play excerpts despite my plans for 
them to read multiple texts. (One student, Shinjiro, brought a reading text from one of his classes, "Children of the River" by Linda Crew, which proved suitable for intonation practice because of the large amount of dialogue in it, but all of the other students read either "the Collection" or "Ylla.")

If I perceived that the students did not understand the text, I took time to explain the meaning of difficult syntax and/or advanced vocabulary. The texts selected for reading were generally of an appropriate level for the students, but at times it was still necessary to explain syntax and vocabulary. I would ask the students to tell me when they did not understand some part of the text so that I knew what to explain to them. The purpose of these explanations was to keep the activity meaningful and interesting to them.

As the students read, I provided feedback on the accuracy of their intonation patterns. For example, if the students used a non-native-like contour, I read the sentence for the students so as to model the native-like contour and then had them read it again. One of my teaching objectives was to have the students learn to monitor their own intonational accuracy, so they were asked during the exit interview if and how their pronunciation has changed.

After each tutoring session, I wrote brief descriptive notes in a log in order to track what techniques I used besides oral reading and to document any difficulties that arose with using oral reading as a practice technique. I also recorded some of the tutoring sessions so that I could refer to the recordings if there was ambiguity in the teaching log. 


\section{e. Post-test and exit interview.}

After seven weeks of this intervention, I administered a post-test parallel to the pre-test, but with different reading passages from short stories carefully selected according to the same criteria (vocabulary level, syntactic complexity, and presence of the four intonation contours) as used for the pre-test. As with the pre-test, the post-test was recored on a MacBook using the built-in microphone. I chose an excerpt from "An Ordinary Day, with Peanuts" by Shirley Jackson (Jackson, 2008) and the complete text of “The Father” by Björnstjerne Björnson, translated by R.B. Anderson (Björnson, 2010). As with the pre-test, I modified the stories to reduce the vocabulary level and increase the number of intonation contours of certain types when necessary. The sentence type counts for each text are listed in Tables 6 and 7: 
Table 6

Sentence type counts for "The Father"

\begin{tabular}{|l|c|c|}
\hline Sentence Type & Number in Unmodified Text & Number in Modified Text \\
\hline Definite statements & over 10 & over 10 \\
\hline Yes/no questions & 7 & 6 \\
\hline$W h$-questions & 3 & 6 \\
\hline Tag questions & 0 & 6 \\
\hline
\end{tabular}

Table 7

Sentence type counts for an excerpt from "An Ordinary Day, with Peanuts"

\begin{tabular}{|l|c|c|}
\hline Sentence Type & Number in Unmodified Text & Number in Modified Text \\
\hline Definite statements & over 10 & over 10 \\
\hline Yes/no questions & 8 & 8 \\
\hline Wh-questions & 3 & 4 \\
\hline Tag questions & 0 & 6 \\
\hline
\end{tabular}

In addition to the post-test, I asked a colleague to interview each student about their perception of the effectiveness of the tutoring sessions. The interview questions (see Appendix B) concentrated on asking the students if they thought that the tutoring improved their intonational accuracy and if it raised their awareness of their own pronunciation. In addition, the interviews were recorded using an Olympus WS-331M so that some of the utterances produced could be used to analyze the students' conversational use of intonation contours. 
I asked a NS colleague to interview each student after our last tutoring session rather than interviewing them myself in order to encourage the students to give accurate and honest feedback about the intervention. (If I had interviewed the students myself, the students would have been likely to give only positive feedback.) I chose a student peer who was as close as possible to the age of the participants' profile.

\section{4) Data Analysis}

Analysis of the students' intonational accuracy was done by listening to the audio recordings of sentences from the pre- and post-tests, questionnaire responses, and exit interviews. I asked three NSs to judge all of the quantitative data set after they had been trained (as explained below), and I also judged all of the data myself.

After I had recorded each oral reading pre-test and post-test using Garage Band (version 3.0.4), I extracted ten examples of each of the four contour types from each of the two tests, resulting in eight categories. I converted these into individual .m4a or .mp4 files using Fission (version 1.6.8.). I then assigned each utterance a unique identifier which indicated the participant's pseudonym, whether the utterance was from the pre-test or post-test, which story the utterance came from, which contour type it was, and a number showing which sentence from the story it was. For the spontaneous utterances from the questionnaires and exit interviews, I had noted where the participants asked questions while listening to the recordings and putting summaries of their answers into a spreadsheet. Later, I extracted all of these questions and converted them into .m4a or .mp4 files. Since most of the utterances from the questionnaires and exit interviews were 
definite statements, I chose the first ten clearly articulated definite statements from each participants' respective questionnaire and interview recordings.

To prepare the data for rating, I took the data set of recorded utterances and selected the first ten of each contour type from the pre-test and post-test sets, all of the questions from the initial questionnaires and exit interviews, as well as ten definite statements from the initial interviews and exit interviews. (For the pre- and post-test sentences, I excluded sentences that were exceptions to the four default contours, sentences with difficult vocabulary and/or syntax, and sentences with poor recording quality.) I assigned a number to each utterance using a random number generator. The checklist provided to the raters listed the utterances by their numbers. Since the utterances were randomized, the other raters did not know which utterances were recorded before the teaching intervention and which were recorded after the intervention. (I acknowledge that I usually knew which utterances came from which data sub-set, but the other raters did not.)

I found three NSs of English to serve as raters. Using several raters helped to control for one rater making an error due to hearing an utterance incorrectly. To train the raters on how to code the data, I first explained what the four intonation contours were. The contours of these sentences were compared to the ideal standard intonation contours in Celce-Murcia, et al. (1996) and marked as having native-like, non-native-like, or ambiguous intonation. For example, if a student had read "We went to the beach today and flew our kites" (a definite statement) with a flat contour instead of the native-like 
final falling contour, the raters were to mark the utterance as "non-native-like." I defined the contours primarily in terms of their boundary tones. I told the raters to judge the utterances by only considering the intonation at the end of the sentence compared to the rest of the sentence (that is, how the boundary tone contrasted with the previous tone or tones in the sentence). I also specifically asked them to mark monotonic utterances and any utterances containing uptalk at the end as non-native like.

Since the raters could not understand the meaning of some utterances because of the heavy accents of some participants, I told the raters what the sentence type for each utterance was. (I made sure to say each sentence type with the same intonation so as not to give the raters cues about how they should judge the utterances.) Then the raters chose if they thought the correct boundary tone for that sentence type was present. The raters told me that informing them of the sentence type allowed them to concentrate on only listening to the intonation rather than attempting to understand the meaning of the utterances. Five utterances were discarded because none of us could determine what sentence type(s) they were because of the poor recording quality or the participants' accents.

With regard to the training, we first rated ten example utterances together using the checklist. (The example utterances came from the recordings of the pre-tests of the participants who did not complete the full set of tutoring sessions). We rated sets of five utterances at a time until we had achieved perfect agreement in our judgments. We achieved that level of agreement (five out of five) on the third set of recordings, thus 
indicating that such judgments were easy to make even for judges with little or no educational background in linguistics.

Once the raters were comfortable with the rating procedure and had achieved one hundred percent accuracy, I played the data recordings for them and the raters marked their judgments on the checklist. Including breaks, the rating took about nine hours and was done over two consecutive days. The raters were allowed to listen to a recording up to three times, but I told them that they could only change their judgment for a particular utterance once because I wanted them to rely on their NS intuition as much as possible. Since the data was a large set of utterances $(n=878)$, breaks were taken at least every hundred utterances (about every twenty minutes).

I also rated the data myself during the rating sessions. Later, I put all of the rater judgments into a spreadsheet. (One rater had judged seven utterances as ambiguous, but she had noted next to her marks for those that she had done so because they were monotonic. I had explained in the training that monotonic utterances were to be judged as non-native-like, so I changed those judgments of hers to non-native-like).

Using the data in the spreadsheet and an online statistical calculator called ReCal to compute inter-rater reliability (Freelon, 2011), I statistically determined the level of inter-rater reliability. An inter-rater reliability coefficient of at least 0.80 was desired, but the achieved reliability coefficient was only 0.55 (moderate agreement). (I originally thought that a minimum of 0.90 would be best, but as Fleiss' kappa is relatively conservative, I changed the standard to 0.80 , which indicates outstanding inter-rater 
reliability [Texasoft, 2008, citing Landis \& Koch, 1977].) I used Fleiss' kappa because that statistical test is suitable for determining inter-rater reliability when there are more than two raters (there were four raters including myself; Texasoft, 2008, citing Fleiss, 1981). Using Fleiss' kappa instead of simply a percentage of inter-rater agreement helped to adjust for chance. In addition, Fleiss' kappa is a more conservative measure of interrater reliability than a simple percentage. For reasons that I explain under study limitations in the discussion section, I excluded the most unreliable rater and recalculated Fleiss' kappa, which then increased to 0.65 (substantial agreement).

After we had rated the data set, I put all the ratings into a spreadsheet and calculated the percentage of native-like utterances out of all native-like and non-nativelike utterances (excluding utterances rated as ambiguous) separately for the preintervention data (questionnaire and pre-test) and the post-intervention data (exit interview and post-test). Next, I compared the percentages for the pre- and post-tests to determine if and how the participants' intonational accuracy had improved. I also calculated the overall pre-test and post-test intonational accuracy percentages for all participants in order to assess the effectiveness of the teaching intervention on improving the intonation of the whole participant group.

To analyze the more qualitative data set collected during the initial questionnaires and the exit interviews, I listened to the recordings of the participants' responses and typed a summary of how each participant answered into a spreadsheet. Later, I looked for patterns in the participants' responses and wrote summaries of each set of answers 
Running head: TEACHING INTONATION PATTERNS... 57 generalizing what most participants had said and pointing out the exceptions to those generalizations. The methodology sub-section on participant characteristics is the result of my analysis of the questionnaire responses. A summary of the analysis of the exit interview responses, which I used to answer the research questions concerning participant attitudes, appears in a results sub-section titled "Exit interviews." With this explanation of how I analyzed the data for this study, I next explain the results of my analysis. 


\section{Results}

In this results section, I present the conclusions of my data analysis by first considering the quantitative data in terms of the first research question and next considering the qualitative data in terms of the second research question.

\section{1) Research Question 1: Intonational Accuracy Improvement}

The first question that I sought to answer was if and how the participants' intonational accuracy (compared to native-speaker norms) improved. I compared the four data sub-sets by grouping them as either pre-intervention (questionnaires and pre-tests) or post-intervention (post-tests and exit interviews). As stated previously, the data consisted of 878 sentences which I extracted and randomized. (There were between 104 and 114 sentences per participant.) Counts for each participant by data source and sentence type are shown in Table 8. 
Table 8

Tokens counts categorized by participant, data source, and sentence type

\begin{tabular}{|l|l|l|l|l|l|l|l|l|l|l|l|l|l|l|l|l|l|}
\hline & \multicolumn{10}{|c|}{ Pre-test } \\
\hline & \multicolumn{11}{|c|}{ Questionnaire } & \multicolumn{10}{|c|}{ Post-test } \\
\hline & D & W & Y & T & D & W & Y & T & D & W & Y & T & D & W & Y & T \\
\hline Betty & 10 & 7 & 1 & 0 & 10 & 10 & 10 & 10 & 10 & 10 & 10 & 10 & 10 & 2 & 3 & 0 \\
\hline Dan & 10 & 1 & 2 & 1 & 10 & 10 & 10 & 10 & 10 & 10 & 10 & 10 & 10 & 1 & 1 & 1 \\
\hline Long & 10 & 1 & 1 & 0 & 10 & 10 & 10 & 10 & 10 & 10 & 10 & 10 & 10 & 0 & 1 & 1 \\
\hline Lulu & 10 & 1 & 1 & 0 & 10 & 10 & 10 & 10 & 10 & 10 & 10 & 10 & 10 & 3 & 2 & 2 \\
\hline Ray & 10 & 1 & 2 & 0 & 10 & 10 & 10 & 10 & 10 & 10 & 10 & 10 & 10 & 4 & 6 & 1 \\
\hline Shinjiro & 10 & 4 & 1 & 1 & 10 & 10 & 10 & 10 & 10 & 10 & 10 & 10 & 10 & 3 & 0 & 0 \\
\hline Simon & 10 & 2 & 3 & 0 & 10 & 10 & 10 & 10 & 10 & 10 & 10 & 10 & 10 & 3 & 1 & 0 \\
\hline Water & 10 & 3 & 7 & 1 & 10 & 10 & 10 & 10 & 10 & 10 & 10 & 10 & 10 & 1 & 1 & 0 \\
\hline
\end{tabular}

Note. $\mathrm{D}=$ definite statements; $\mathrm{W}=w$ h-questions; $\mathrm{Y}=$ yes/no questions; $\mathrm{T}=$ tag questions.

Four raters including myself rated the utterances as native-like, non-native-like, or ambiguous. Eleven utterances were removed from the data set during the rating because the recording was too unclear, the sentence was an exception to the four default intonation patterns which I focused on in the teaching intervention, or there was a nonEnglish word in the sentence. I excluded one rater's judgments from the final analysis because his ratings were too unreliable compared to the other three raters (including myself). Overall, the participants showed some improvement in their intonational accuracy, although they still usually fell short of 100\% accuracy (although the participants were judged as $100 \%$ native-like in at least one category, namely a single sentence type from a single source), indicating that all of the participants could have used 
more intonation instruction or that they did not acquire native-like accuracy fully for other reasons.

To make a broad comparison of the pre- and post-intervention data sub-sets, I calculated the frequency of intonational accuracy for sub-sets of data defined by sentence type, participant, and data source (pre-test, post-test, questionnaire, and exit interview). I calculated this frequency by adding all native-like (NL) judgments together and dividing by NL plus non-native-like (NNL) judgments. To determine if the participants' change in intonational accuracy rates was statistically significant, I ran a Wilcoxon Signed Ranks Test, which is considered the appropriate statistical test for comparing pre- and post-test data, using these accuracy percentages. The test indicated that there was a strongly significant change in the participants' intonational accuracy rates comparing their performance before the teaching intervention to their performance afterward $(Z=2.779$, $P=0.005, \alpha=0.05)$. The null hypothesis, therefore, is not supported, and there was a relationship between receiving the instruction and improvement in intonational accuracy.

Given these levels of statistical significance, there is strong evidence that the participants' intonational accuracy improved by comparing their performance before and after the teaching intervention. Therefore, the teaching intervention was likely effective in improving the participants' command of the four intonation patterns. However, this finding does not rule out the possibility that the participants' intonational accuracy could have improved due to the influence of extraneous variables such as simply being in an English-speaking environment for a longer period of time. As I will explain in the 
discussion section, I could have accounted for this variable if I had included a control group in the study design.

As shown in Table 9, the pre-intervention accuracy rates grouped by sentence type were all lower than the post-intervention rates, showing that the participants improved overall in their intonational accuracy. The improvements in accuracy for definite statements and yes/no questions were $7.8 \%$ and $5.2 \%$, respectively. The largest improvement was over $11.2 \%$ for wh-questions, and the accuracy of tag questions improved $8.3 \%$. The overall average improvement in accuracy for all sentence types was $8.2 \%$.

Table 9

Intonational accuracy rates by sentence type comparing pre- and post-intervention rates (considering both oral reading and spontaneous speech data)

\begin{tabular}{|l|l|l|l|l|l|}
\hline & average & $\begin{array}{l}\text { definite } \\
\text { statements }\end{array}$ & $w h$-questions & $\begin{array}{l}\text { yes/no } \\
\text { questions }\end{array}$ & $\begin{array}{l}\text { tag } \\
\text { questions }\end{array}$ \\
\hline $\begin{array}{l}\text { Pre-teaching } \\
\text { intervention }\end{array}$ & $76.9 \%$ & $80.6 \%$ & $79.8 \%$ & $76.6 \%$ & $70.8 \%$ \\
\hline $\begin{array}{l}\text { Post-teaching } \\
\text { intervention }\end{array}$ & $85.1 \%$ & $88.4 \%$ & $91.0 \%$ & $81.8 \%$ & $79.1 \%$ \\
\hline Improvement & $8.2 \%$ & $7.8 \%$ & $11.2 \%$ & $5.2 \%$ & $8.3 \%$ \\
\hline
\end{tabular}

One limitation of the above results is that the more naturalistic data from the questionnaires and exit interviews was limited. Some participants did not use certain sentence types at all during the questionnaires or exit interviews, meaning that the data sub-sets for those sentence types were deficient. The relative lack of more naturalistic 
data also means that the averages quoted in Table 9 for improvements for particular sentence types gives greater weight to the pre- and post-test data than to the more naturalistic data. In addition, there were more definite statements, perhaps suggesting that those results were more representative. To determine if the participants improved when only considering the oral reading data, I removed the more naturalistic data and recomputed averages for only the oral reading pre- and post-tests, as shown in Table 10. The difference in improvement over all sentence types was somewhat larger at $12.3 \%$. Improvements in definite statements, wh-questions, and yes/no questions were $11.7 \%$, $5.7 \%$, and $11.8 \%$, respectively. The improvement in tag questions was much larger at $19.8 \%$. Since the participants' improvement was generally larger in the oral reading data, it is possible that what they learned while practicing intonation through oral reading may not have transferred fully to their conversational speech.

Table 10

Intonational accuracy rates by sentence type comparing pre- and post-test rates (considering only oral reading data)

\begin{tabular}{|l|l|l|l|l|l|}
\hline & average & $\begin{array}{l}\text { definite } \\
\text { statements }\end{array}$ & wh-questions & $\begin{array}{l}\text { yes/no } \\
\text { questions }\end{array}$ & $\begin{array}{l}\text { tag } \\
\text { questions }\end{array}$ \\
\hline Pre-test & $80.1 \%$ & $84.5 \%$ & $85.2 \%$ & $74.8 \%$ & $76.0 \%$ \\
\hline Post-test & $92.4 \%$ & $96.2 \%$ & $90.9 \%$ & $86.6 \%$ & $95.8 \%$ \\
\hline Improvement & $12.3 \%$ & $11.7 \%$ & $5.7 \%$ & $11.8 \%$ & $19.8 \%$ \\
\hline
\end{tabular}

When comparing all of the pre-intervention data with the post-intervention data by participant (including both oral reading and more naturalistic data), all of the 
participants individually showed some improvement in their accuracy rates, as shown in Table 11 below. However, Wilcoxon Signed Ranks Tests indicated that only Lulu improved to a statistically significant degree. Nevertheless, considering percentage of improvement, five of the participants improved more than $10 \%$. Although two participant's accuracy rates showed an improvement of only just under $4 \%$, one participant's accuracy improved over $21 \%$. However, this calculation was done by adding the total number of NL judgments and dividing by NL plus NNL judgments, and thereby undervalues the more naturalistic data which were fewer in number.

\section{Table 11}

Intonational accuracy rates by participant

\begin{tabular}{|l|l|l|l|l|}
\hline & $\begin{array}{l}\text { Pre- } \\
\text { intervention }\end{array}$ & $\begin{array}{l}\text { Post- } \\
\text { intervention }\end{array}$ & Improvement & $\begin{array}{l}\text { Statistically significant? } \\
(\alpha=0.05)\end{array}$ \\
\hline Betty & $85.1 \%$ & $95.1 \%$ & $10.0 \%$ & No $(p=0.463 ; Z=-0.734)$ \\
\hline Dan & $83.3 \%$ & $92.8 \%$ & $9.5 \%$ & No $(p=0.233 ; Z=-1.192)$ \\
\hline Long & $74.3 \%$ & $86.7 \%$ & $12.3 \%$ & No $(p=0.600 ; Z=-0.524)$ \\
\hline Lulu & $70.9 \%$ & $92.4 \%$ & $21.5 \%$ & Yes $(p=0.028 ; Z=-2.201)$ \\
\hline Ray & $77.6 \%$ & $81.5 \%$ & $3.9 \%$ & No $(p=1.000 ; Z=-0.000)$ \\
\hline Shinjiro & $83.5 \%$ & $87.1 \%$ & $3.6 \%$ & No $(p=0.588 ; Z=-0.542)$ \\
\hline Simon & $79.4 \%$ & $89.7 \%$ & $10.3 \%$ & $\begin{array}{l}\text { No, but close }(p=0.075 ; Z=- \\
1.782)\end{array}$ \\
\hline Water & $77.8 \%$ & $90.9 \%$ & $13.1 \%$ & $\begin{array}{l}\text { No, but close }(p=0.075 ; Z=- \\
1.782)\end{array}$ \\
\hline
\end{tabular}

Another way to consider these data is to average the frequency of NL judgments for each sentence type from each data source (questionnaires, pre- and post-tests, and exit interviews). This calculation gives more weight to the more naturalistic data than the 
calculation used for the analysis above. A comparison of the pre- and post-teaching intervention data sub-sets in this way also reveals that all the participants improved, as shown in Table 12. (The statistical significance values are exactly the same as in Table 11, so they are not repeated in Table 12.) Using this analysis, it appears that all participants but one improved $8 \%$ or more. Long improved only $2.6 \%$ using this statistic, probably because of low accuracy rates for the question sentence types based on only three rater judgments.

Table 12

Averages of intonational accuracy rates by participant (giving more weight to naturalistic data)

\begin{tabular}{|l|l|l|l|}
\hline & Pre-intervention & Post-intervention & Improvement \\
\hline Betty & $86.9 \%$ & $96.2 \%$ & $9.3 \%$ \\
\hline Dan & $73.6 \%$ & $85.7 \%$ & $12.1 \%$ \\
\hline Long & $72.3 \%$ & $74.8 \%$ & $2.6 \%$ \\
\hline Lulu & $70.5 \%$ & $78.7 \%$ & $8.2 \%$ \\
\hline Ray & $73.6 \%$ & $83.7 \%$ & $10.2 \%$ \\
\hline Shinjiro & $72.5 \%$ & $86.5 \%$ & $14.0 \%$ \\
\hline Simon & $80.6 \%$ & $90.4 \%$ & $9.8 \%$ \\
\hline Water & $78.7 \%$ & $88.9 \%$ & $9.2 \%$ \\
\hline
\end{tabular}

Excluding the accuracy rates for the sentence types from particular data sources based on less than ten rater judgments (as shown in Table 13), Long's accuracy rate was over $13 \%$. Using this calculation (excluding accuracy rates based on less than ten judgments), all of the participants' accuracy rates, except Ray's and Shinjiro's, improved 
$9 \%$ or more. However, none of the results from the analysis excluding the small data subsets were statistically significant according to the Wilcoxon Signed Ranks Tests except for Lulu's. In Shinjiro's case, his relative lack of improvement (only $2.5 \%$ ) was probably due to his use of uptalk on definite statements in the exit interview. The cause of Ray's improvement of only $1.8 \%$ is unclear.

Table 13

Intonational accuracy rates by participant, excluding small data sub-sets

\begin{tabular}{|l|l|l|l|l|}
\hline & Pre-intervention & Post-intervention & Improvement & $\begin{array}{l}\text { Statistically significant? } \\
(\alpha=0.05)\end{array}$ \\
\hline Betty & $84.8 \%$ & $94.6 \%$ & $9.8 \%$ & No $(p=0.463 ; Z=-0.734)$ \\
\hline Dan & $84.4 \%$ & $93.7 \%$ & $9.3 \%$ & No $(p=0.233 ; Z=-1.192)$ \\
\hline Long & $74.5 \%$ & $88.1 \%$ & $13.6 \%$ & No $(p=0.600 ; Z=-0.524$ \\
\hline Lulu & $71.3 \%$ & $95.9 \%$ & $24.6 \%$ & Yes $(p=0.028 ; Z=-2.201)$ \\
\hline Ray & $79.6 \%$ & $81.4 \%$ & $1.8 \%$ & No $(p=1.000 ; Z=-0.000)$ \\
\hline Shinjiro & $84.6 \%$ & $87.2 \%$ & $2.5 \%$ & No $(p=0.588 ; Z=-0.542)$ \\
\hline Simon & $78.7 \%$ & $89.0 \%$ & $10.4 \%$ & $\begin{array}{l}\text { No, but close }(p=0.075 ; Z=- \\
1.782)\end{array}$ \\
\hline Water & $75.6 \%$ & $91.1 \%$ & $15.5 \%$ & $\begin{array}{l}\text { No, but close }(p=0.075 ; Z=- \\
1.782)\end{array}$ \\
\hline
\end{tabular}

No matter which method of calculation I used, the students' intonational accuracy improved after the students had received my instruction, indicating that the teaching intervention may have been effective in improving their intonational accuracy.

\section{2) Research Question 2: Participant Attitudes and Perceptions}

In looking at what role affect played in the teaching intervention, I considered what the participants reported in the exit interviews about their perceived improvement, 
their awareness of their own intonation, and their feelings about the teaching techniques that I used. In general, the participants believed that the teaching improved their intonation and that they had become more aware of their intonation as a result of the teaching provided. In addition, most of them reported that they enjoyed the teaching to some extent. These results show that explicit instruction with oral reading practice is a useful approach to teaching intonation when considering the students' affective reaction to the instruction.

\section{a. Perception of intonational accuracy improvement}

Six of the participants reported that their intonation in particular had improved as a result of the tutoring. Two of the participants may have interpreted the question about changes in pronunciation as including changes to the segmental aspects of their pronunciation, which was a subject on which all but one of the participants received instruction in the second half of the tutoring sessions, but all of the participants reported that their pronunciation changed as a result of the tutoring.

As with the previous question about improvement in pronunciation, the question that asked if the students would change their pronunciation as a result of this tutoring may have been misinterpreted. All of the students reported that they would change their pronunciation in the future, although one commented that the teaching intervention was not long enough to allow him to change his pronunciation completely.

Overall, the participants clearly found the teaching useful and believed that the teaching had changed their pronunciation. 


\section{b. Awareness}

I assessed the participant's feelings about studying through oral reading and about studying English intonation through a semantic differential scale. The results of the semantic differential (on a scale of 1 to 6) can be seen in Tables 14 and 15. A low score indicates that the participant ranked the item in question as closer to the concept on the left side, and a high score indicates a mark closer to the right side concept.

Table 14

Feelings about studying English intonation (exit interview question 4.b.)

\begin{tabular}{|l|l|l|l|l|l|}
\hline & Useful/Useless & $\begin{array}{l}\text { Frustrating/ } \\
\text { Not Frustrating }\end{array}$ & Not Fun/Fun & Interesting/Boring & Confusing/Clear \\
\hline Betty & 2 & 6 & 4 & 3 & 6 \\
\hline Dan & 1 & 6 & 6 & 2 & 6 \\
\hline Long & 1 & 6 & 4 & 2 & 5 \\
\hline Lulu & 1 & 2 & 4 & 5 & 3 \\
\hline Ray & 1 & 6 & 6 & 1 & 6 \\
\hline Shinjiro & 1 & 3 & 5 & 3 & 3 \\
\hline Simon & 1 & 6 & 4 & 3 & 6 \\
\hline Water & 5 & 2 & 5 & 1 & 3 \\
\hline Average rating & 1.63 & 4.63 & 4.75 & 2.38 & 4.75 \\
\hline
\end{tabular}


Table 15

Participant feelings about oral reading (exit interview question 4.a.)

\begin{tabular}{|l|l|l|l|l|}
\hline & Useful/Useless & $\begin{array}{l}\text { Frustrating/ } \\
\text { Not Frustrating }\end{array}$ & Not Fun/Fun & Interesting/Boring \\
\hline Betty & 1 & 6 & 5 & 2 \\
\hline Dan & 1 & 6 & 6 & 1 \\
\hline Long & 1 & 6 & 5 & 1 \\
\hline Lulu & 1 & 3 & 1 & 1 \\
\hline Ray & 1 & 5 & 6 & 1 \\
\hline Shinjiro & 1 & 2 & 5 & 1 \\
\hline Simon & 1 & 5 & 5 & 1 \\
\hline Water & 1 & 3 & 5 & 5 \\
\hline Average rating & 1 & 4.5 & 4.75 & 1.88 \\
\hline
\end{tabular}

All of the participants reported during the exit interviews that their understanding of intonation improved as a result of the tutoring. On the semantic differential, half of the participants marked that they thought that their understanding of English intonation was clear and not confused at all, as shown in Table 14. (Since there were six rankings possible [an even number], the participants could not mark an item as being neutral.) Another participant marked it as mostly clear, and three participants' marks leaned toward the "confused" end of the scale. These responses indicate that the explanations of English intonation were clear enough to be effective although the explanations were difficult for some of the participants to understand. 


\section{c. Affect}

The participants' marks on the semantic differential scale were mostly positive, indicating that they thought the teaching was useful, interesting, fun, and not too frustrating.

Every participant thought that studying English through oral reading was useful (see Table 15). Five of the participants thought that studying this way was not very frustrating, but the other three reported that it was at least somewhat frustrating. One participant reported that oral reading was neither fun nor very interesting, showing that she did not enjoy the teaching technique, but the other participants indicated that it was at least somewhat fun and interesting.

The participants' reactions to the intonation instruction (see Table 14) were similar in that they generally found it useful, fun, somewhat interesting, and clear. However, one participant marked that the intonation instruction was not very useful and that it was somewhat frustrating and confusing. Nevertheless, she marked the intonation instruction as somewhat interesting and fun. Another participant thought that it was useful, but she also found it somewhat frustrating and confusing. The other six participants were much more positive.

The overall reactions of the participants to the oral reading practice and English intonation instruction was mostly positive, showing that this group of students is generally open to the kind of teaching used in this study. 


\section{d. Participant perception of the instruction}

After the tutoring had concluded, a colleague of mine interviewed the participants and asked them about how well they learned through the tutoring, if the instruction could be improved (and if so, how), and if they thought the tutoring was useful enough to recommend it to one of their classmates.

Based on the participants' answers to the exit interviews questions, all the participants found the teaching useful and thought that they had learned from it. Except for one participant who appeared to have misinterpreted the question, all the participants reported that they learned through the drawings of the intonation patterns (see Figure 1). All of them also thought that they learned through listening to my explanations of the intonation patterns. Seven of the participants reported that they thought that they learned a significant amount through practicing with oral reading, but one reported that she only learned "some, not a lot." Six of the participants agreed that they had learned from me correcting their intonation. However, one stated that she did not learn in this way because she "always forgot" the corrections that I gave her (the eighth participant's response was missing from the recording). In sum, the participants reported that they learned from the teaching intervention.

The participants responded with a variety of comments on what about the teaching was useful and what should be changed. Two participants reported that they thought the explanations of English intonation patterns that I gave were good. One particularly appreciated my explanations of the story's plot as she read. Another, despite 
saying that she could not remember the corrections I gave her, reported that she thought the immediate corrections on incorrect intonation that I gave as she read were good. Other participants appreciated my use of body language in explanations and my rereading parts of the stories.

In terms of ways to improve the teaching sessions, two participants noted that the teaching sessions were very short. They felt that more instruction time may have allowed them to learn more. In addition, one participant suggested having a session outside of school, such as in a restaurant, in order to practice in a more natural environment. Besides this feedback on how to improve the sessions, two participants commented on the cultural component of the stories. One participant thought that "Hills Like White Elephants" was especially difficult to understand from his cultural perspective because of the sub-text in that story concerning abortion. Another said that she would have liked to have had me incorporate more cultural information into the sessions. These comments may be useful to pronunciation teachers as they consider how to design their lessons.

When asked if they would recommend this kind of tutoring to another student, all the participants reported that they would. Three of them commented that it was helpful or useful to them. One Chinese participant noted the usefulness of this tutoring to Chinese students considering how pronunciation teaching is neglected in China. The single Japanese participant commented that this kind of tutoring addresses a need among Japanese learners to improve their speaking. Even if some of the participants did not 
enjoy the teaching at times (as reported on the semantic differential), they reported that they would recommend tutoring like this, showing that they found it useful.

Based on the participant responses to the exit interview questions, the participants appreciated the instruction that they received. Their comments were not unequivocally positive, but generally the participants thought that the teaching was beneficial and interesting enough. Therefore, it is possible that East Asian students in general are open to studying intonation through oral reading and may find this teaching technique helpful to them. 


\section{Discussion and Application}

What then does this study have to contribute to applied linguistics research and our understanding of intonation teaching? Before this question can be answered, I must

first consider the limitations of the study's design. Next, I will apply this study's findings by making recommendations for future applied linguistics research related to this study. After that, I will consider the specific application of this study to teaching pronunciation, especially in the ESL context.

\section{1) Study Limitations}

There is little reason to doubt the accuracy of the qualitative data for these participants (although the question remains as to how generalizable the findings are). Since a colleague of mine conducted the exit interviews, the participants most likely answered honestly. However, the participants knew that the interviewer was also a friend of mine, so they may have toned down their criticism of the teaching technique. Nevertheless, the participants offered critiques of the teaching technique that may be useful for ESL instructors who wish to teach intonation. The participant group was a convenience sample of East Asian ESL students, and so the qualitative findings of this study could be relevant only to that group of students. The quantitative data, however, had several major limitations.

\section{a) Limitations of the quantitative data}

Although there seemed to be few issues with the qualitative data, the quantitative results were more problematic, especially in terms of rater judgments and data set size. 
The standard of inter-rater reliability coefficient that I set was 0.80 . However, the achieved coefficient was only 0.65 even after I excluded one rater's judgments from the analysis (recall that this was using Fleiss' kappa, a conservative measure). Rater unreliability may have been due to several different factors, including insufficient training, the difficulty of judging pitch accurately, one rater's background, and rater fatigue.

First, the training may have been too short. I spent about 40 minutes explaining to the rater how to categorize the utterances that we were to hear. We achieved $100 \%$ agreement on the third set of utterances. (The first set consisted of ten utterances, and the second and third were five each.) Perhaps more training with several more sets of utterances would have improved rater accuracy.

A second issue was the difficulty of judging pitch accuracy because the raters were not accustomed to doing so and because of the presence of uptalk. Even though one rater was a gifted musician, he told me after the rating that he had trouble at times making judgments on whether the utterances ended in a high or low boundary tone. He said that he understood intellectually what we had been rating, but he sometimes had difficulty making judgments, probably because they had never been required to do so before. In addition, the use of uptalk by some of the participants may have made the rating more difficult. I noticed as we were rating that it was unclear for some definite statements, especially those from the naturalistic data, if the participant was using uptalk (a high rising terminal contour) or if the participant was signaling that $\mathrm{s} /$ he wanted to continue 
speaking (which is usually signaled by a fall-rise terminal contour). As expected, uptalk proved to a contaminating factor that made the rating more difficult for the judges, and the judges were also not used to making judgments like these.

Third, the linguistic background of the raters was an issue. With my training as an ESL teacher, I find that I am more likely to err towards over- rather than undercorrection, which is probably why my judgments were harsher than any of the other raters. I rated more utterances as non-native-like and fewer as native-like than they did. Out of the 867 utterances, I rated 161 as non-native-like, while the other raters rated only 131, 64, and 106 utterances as NNL. In addition, the same rater who had trouble perceiving pitch also told me that he usually gives NNSs "the benefit of the doubt," and this preference was shown in his judgments, for he categorized 99 more utterances as native-like than I did (my total for native-like utterances was 686). That rater judged 785 as native-like, which was also 72 more than either of the other raters (who both rated 713 as native-like). His leniency may be due to the fact that he lived abroad for much of his childhood in various non-English speaking countries and thereby grew accustomed to non-native-like intonation. For this reason, I chose to exclude his ratings from the final analysis since his judgments were too lenient compared to the other raters'.

A fourth factor that may have influenced the raters' judgments was fatigue. We took breaks of at least five minutes every 100 utterances or so (which took, on average, just over 20 minutes to judge), but counting breaks and the time spent rating, the data took about nine hours to judge. It was not possible to rate all 878 recordings in one day 
either; we had to met on two consecutive days to rate all of the data. For future studies of this kind, I would recommend giving each rater no more than three or four hundred utterances in order to keep the raters at their peak level of awareness. With data sets over 400 utterances, it would be best to have different raters judge each set in order to prevent fatigue.

The second major issue for the quantitative data set was its size. As mentioned before, the more naturalistic data from the questionnaires and exit interviews was missing some sentence types for some participants, resulting in 13 blank cells out of 128 (for all utterance types from all sources). Some cells only represented rater judgments on a single utterance. Of the 128 total cells, 79 were based on 25 or more rater judgments. The cells with more rater judgments were for sentences of all types from the pre- and post-tests or were for definite statements from either the questionnaires or exit interviews. A larger data set (i.e. more data that was more naturalistic) would have allowed me to test for statistical significance more.

With the limitations of this study in mind, linguists who conduct studies similar to this one in the future may be able to learn from the limitations of this study and use that knowledge to improve their study design. Nevertheless, despite the drawbacks listed above, the quantitative data analysis results clearly indicated that the participants improved their intonational accuracy when that was measured through oral reading tests, and the participants may also have improved their intonational accuracy in more naturalistic settings, especially their command of definite statement intonation. 


\section{b) Discourse context as a complicating factor}

Perhaps the greatest limitation of this study overall is that it focused on only the default sentence patterns determined by syntactic criteria. Ladd went so far as to say that "it is almost impossible to find consistent associations between grammar and intonation" (1980, p. 139). Instead, Ladd posited that intonation is encoded in the lexicon rather than being determined by the syntax of a sentence. Levis noted that "[syntactic-based] rules offer a seductive allure of certainty to both teachers and learners" (2005, p. 358-359). Various discourse and pragmatic factors complicate the teaching of intonation. However, Ford and Thompson (1996), in contrast to Ladd's extreme position, found that the ends of intonational contours and the ends of syntactic units very reliably coincide, indicating that syntax can help predict intonation.

In the teaching intervention for this study, I taught pragmatic and discourse-based guidelines for intonation, but the rating of the quantitative data (from all sources) was based on a simplified approach to intonation that focused on how syntax may determine intonation. During the rater training, I instructed the raters to mark sentence types as native-like, non-native-like, or ambiguous based on the default boundary tones associated with those sentence types. However, it is open for interpretation whether judging the intonation of those utterances based on syntactic criteria alone was valid. As stated in the literature review, I had to simplify choosing which boundary tone was appropriate for a particular utterance, for considering discourse criteria would have required the raters to analyze the sentence in its original context and determine based on the context what 
boundary tone was appropriate. For example, as Levis (2005) also stated, yes/no questions in particular may have rising or falling intonation depending on factors such as the speaker's expectation of certainty in the answer to the question (p. 359). In "Bliss" (one of the stories used for the pre-test), a young man appears to exclaim with certainty, "Do you believe me now?", thereby making the choice of a low boundary tone potentially appropriate, although based on syntactic criteria alone, a high boundary tone would be selected. (By stressing "believe," the utterance takes on an insistent tone that would be appropriate for the context of the young man trying to convince his parents of how wonderful the event that just happened to the young man was.) If the raters had analyzed the context of each utterance first, the rating would have taken much more time, which would have significantly restricted the number of utterances rated, thereby forcing me to base the analysis of the participant's improvement in intonational accuracy on far fewer utterances.

On the other hand, what this study tested was not so much if the participants had acquired native-like intonation, but if the participants had learned to use the default settings for particular intonation contours as a result of the teaching intervention. According to the results, they appear to have done so. Therefore, as the participants continue to listen to NSs converse using intonation for a variety of effects about which I did not instruct them, my hope is that the participants realize that I was only able to teach them a simplification of the complex English intonation system. During many of the tutoring sessions, I pointed out to the students that I was making generalizations, but that 
there are also exceptions to the rules that I taught them. Since all of the students claimed to be more aware of intonation in English now, my hope is that they will use this new awareness to refine their intonation more and gain a fuller understanding of the complexities of intonation in English.

\section{2) Application to Future Research}

Although this study was limited in several respects, the results are relevant to future research. When thinking of how future research might use the findings of this study, I will consider six aspects of study design: the kind of participant sample used, the timing of the post-test, the need for naturalistic data, the rating procedure, the participants, and the types of data collected.

When I first conceived of this study, I wanted to compare two different groups of ESL students in two different classes at a college: one group serving as the control group, the other as the experimental group. I would then administer an oral reading pre-test to all the students in both classes, teach the experimental class English intonation using the technique described in this study for a term, administer a post-test to both classes, and finally compare the results. This original plan of mine proved impractical for a thesis, but one potential direction for future research would be to conduct such a study. A study of this design would clarify if the students' improvement in intonation accuracy was due mostly to the teaching or if there were extraneous variables involved.

Besides having a control group, this study would also have been stronger if I had used a delayed post-test. Unfortunately, I did not have the time to administer a post-test 
several weeks or months after the study. Having a delayed post-test would have shown whether or not the changes in the participants' intonational accuracy were lasting.

In addition, a question that this study could not answer was about transfer: whether what is learned about intonation through oral reading can transfer to naturalistic contexts. There was too little naturalistic data in this study to draw any definite conclusions. Future studies on oral reading should consider collecting more naturalistic data that can be compared to the oral reading data. Perhaps then we will understand if what students learn while oral reading is transferred to their conversational skills.

Furthermore, intonation research cannot ignore one basic dictum of linguists who study intonation: Discourse and intonation are inseparable. (By “discourse," I am referring to the pragmatic aspects of the discourse context.) Future studies on intonation, whether applicable to ESL teaching or not, must consider the role of intonation in discourse. If I were to conduct this study again, I would redesign the methodology to take into account the importance of discourse in determining intonation. As stated in the subsection on study limitations, analyzing the discourse context would have complicated the rating procedure, but it also could have increased the validity of the study results.

This study focused on teaching one aspect of pronunciation in one language to a group of learners from a particular region, but future research may wish to consider other aspects of pronunciation, other languages, and learners from other regions. This study only had eight participants, all of whom were from East Asia. Researchers in applied linguistics may want to consider how students from other parts of the world respond to 
this kind of instruction. In addition, this study only looked at how to teach English intonation. Researchers who look at languages besides English may want to consider if teaching intonation in their language of interest is needed, and, if so, whether or not oral reading would be an appropriate practice technique with which to assess its effectiveness. Besides these points on the application of this study to research, this study also has applications to teaching other aspects of pronunciation, not only suprasegmental aspects closely related to intonation such as rhythm and stress, but also segmental aspects including consonants and vowels. Oral reading may be useful for practicing several other aspects of pronunciation, not just intonation, because of how it allows the students to concentrate on producing the sounds rather than worrying about grammar and lexicon. The field of linguistics could be further enriched by studies that examine other groups of learners, how intonation can be taught in other languages, and how oral reading may be used to practice other aspects of pronunciation.

Finally, one of the strengths of this study was that it considered both qualitative and quantitative data. Many studies in linguistics look at only one kind of data; however, sometimes researchers can overlook important facets of the situation when they only consider one type of data. With this issue in mind, I designed this study so that I could see the situation through both quantitative and qualitative lenses. In this study, I used quantitative methods (primarily the analysis of NS judgments of recordings) to determine if and how much the students learned. However, those methods were only one part of the study. I also used qualitative methods (the initial questionnaire and exit interview) to see 
how the students reacted to the instruction. In addition, the exit interview also included a quantitative component (the semantic differential). Combining quantitative and qualitative methods bolstered the validity of this study.

Many linguists consider quantitative data more reliable and trustworthy than qualitative data, but qualitative analysis can illuminate patterns that are not clear from quantitative analysis. When possible, researchers in applied linguists should consider how to implement mixed-methods practices in their research, especially when studying how people learn language. Many variables can contribute to how well a person learns a language, so using both quantitative and qualitative methods allows researchers to capture a more complete picture of the situation than either quantitative or qualitative analysis can alone. A mixed-methods approach is especially appropriate when researching the effectiveness of instructional techniques, for the students' reaction to the teaching methods and the degree to which their language skills improved (or failed to improve) are both important to consider.

To return to why I chose to conduct this study, many ELLs have difficulty mastering English intonation. They need explicit intonation instruction to help them correct their pronunciation. By undertaking this study, I was able to help a small group of students improve their intonation. Yet much more work remains to be done. There is a great need for intonation instruction among East Asians especially, so more research is needed that will test how effective other techniques for improving intonation are. Future research should take into account the above recommendations for using control and 
experimental groups, collecting more naturalistic data, considering the role of discourse, researching how oral reading may useful in other teaching situations, and mixing qualitative and quantitative data analysis techniques. This study has shed light on how practical intonation research might be better designed in the future.

\section{3) Application to Pronunciation Teaching}

The results from this study indicate that oral reading may be an effective technique for teaching intonation in a tutoring context. When considering how the oral reading technique might apply to a classroom situation, it is important to remember that oral reading is often best done with one student individually. Otherwise, only one student reads while the others must silently follow along. Some classes are disciplined enough to do this, but others may become bored quickly. If teachers can train their students to correct each other's intonation, pair practice with oral reading may be possible. (Training students to correct each other while doing oral reading pair practice is also another potential direction for future studies.) Although the usefulness of oral reading may be limited in large classes, this study shows that oral reading practice can be used effectively in a tutoring situation. Oral reading has the advantage of allowing students to focus on pronunciation, and it also may be useful if interesting texts are chosen for the students to read.

In addition to lessening the students' cognitive load by providing the grammatical and lexical choices for them, oral reading may be useful if the texts read are interesting to the students. When I asked the students during the teaching intervention if they were 
enjoying the stories we were reading, they said that the stories were interesting, and most of the students reported during the exit interviews that they enjoyed reading the stories aloud. The higher level students who read "Ylla" from The Martian Chronicles found that story to be especially interesting, probably because of the author's masterful use of imagery, imagination, and suggestion. If teachers choose texts that are interesting to their students, the students are much more likely to be motivated and strive harder to improve their language skills. Even though using such texts could be a distraction from the focus on pronunciation, it may prevent the students from becoming bored. Initially, using the framework for pronunciation teaching that Morley (1994) proposed, teachers might be wiser to use simpler texts for the dependent practice phase of pronunciation teaching; however, for the guided practice phase, more interesting texts are more appropriate. In sum, pronunciation teachers should consider oral reading as one possible practice technique. This study showed that oral reading can be effectively used to change the intonation patterns of East Asian students, and, although the results of this study were exploratory, pronunciation teachers should determine for themselves if oral reading is a technique that would work for their unique teaching context. 


\section{Conclusion}

I originally conducted this study in order to improve my teaching technique and contribute to the field of applied linguistics by researching a technique that had not been researched before for teaching intonation. I am pleased to report that I accomplished both of these goals: I have increased my confidence as a pronunciation teacher, and I have also shed light on how oral reading may be useful to ESL/EFL teachers. Furthermore, the participants generally enjoyed my teaching and reported that their awareness of intonation had increased. As I had hoped, the students reported after having finished the tutoring that they had a better of understanding of intonation in English, so they now have the ability to better monitor their intonation. Since I was able to teach them only a few intonation patterns, I hope that the participants will expand their intonational repertoire as they interact more with other English speakers.

This study demonstrated that explicit intonation instruction concentrating on just a few common patterns with oral reading as the primary practice mode is effective for improving East Asian students' intonation in a tutoring context. Nevertheless, further research, as always, is needed, especially research that takes into account the inseparability of discourse and intonation. Even so, this study has shed light on how one technique might be useful to pronunciation teachers, and it is my hope that other pronunciation teachers will test for themselves if oral reading practice in the context of explicit pronunciation instruction is a technique they wish to employ. 


\section{References}

Abe, I. (1998). Intonation in Japanese. In Hirst, D., \& Di, C. A. (Ed.s), Intonation systems: A survey of twenty languages (p.360-375). Cambridge, U.K: Cambridge University Press.

Allinder, R.M, Dunse, L., Brunken, C.D., Obermiller-Krolikowski, H.J. (2001). Improving fluency in at-risk readers and students with learning disabilities. Remedial and Special Education, 22(1), p. 48-54. Retrieved from http://rse.sagepub.com/

Anderson-Hsieh, J., Johnson, R., \& Koehler, K. (1992). The relationship between native speaker judgments of nonnative pronunciation and deviance in segmentals, prosody, and syllable structure. Language Learning, 42(4), p. 529-555.

Avery, P. \& Ehrlich, S. (1992). Teaching American English pronunciation. New York:

Oxford

University Press.

Beckman, M.E., Pierrehumbert, J.B. (1986). Intonational structure in Japanese and English. Phonology Yearbook, 3, p. 255-309. Retrieved from http://www.jstor.org.proxy.lib.pdx.edu/action/showPublication? journalCode=phonyear

Björnson, B. (2010). The Father. (R.B. Anderson, trans.) Retrieved from http://www.bartleby.com/195/14.html\#txt1

Bolinger, D. (1978): Intonation across languages. In: J. Greenberg (Ed.), Universals of 
human language, vol. 2, phonology (p. 471-524). Stanford: Stanford University Press. Bolinger, D. (1986). Intonation and its parts: Melody in spoken English. Stanford, CA: Stanford Press.

Bongaerts, T., van Summeren, C., Planken, B., \& Schils, E. (1997). Age and ultimate attainment in the pronunciation of a foreign language. Studies in Second Language Acquisition, 19(4), 447-465. Retrieved from http://www.ling.ohiostate.edu/

Bradbury, R. (1958). The Martian Chronicles. New York, NY: Bantam Books.

Burleson, D.F. (2007). Intonation patterns in English tag questions of Japanese speakers of English as a second language. IULC Working Papers, 7. Retrieved from https://www-indiana-edu.proxy.lib.pdx.edu/ iulcwp/pdfs/07-Burleson4.pdf

Canh, L.V., \& Barnard, R. (2009). Curricular innovation behind closed classroom doors: A Vietnamese case study. Prospect, 24(2). Retrieved from http://www.ameprc.mq.edu.au/resources/prospect

Celce-Murcia, M., Brinton, D., \& Goodwin, J. (1996). Teaching pronunciation: A reference for teachers of English to speakers of other languages. New York: Cambridge University Press.

Chafe, W. (1988). Punctuation and the Prosody of Written Language. Written Communication, 5, p. 395-426. doi:10.1177/0741088388005004001

Chekhov, A. (2010, December 29). Bliss - Wikisource. (M. Fell, trans.) Retrieved from http://en.wikisource.org/wiki/Bliss 
Chen, J.F., Warden, C.A., \& Chang, H.T. Motivators that do not motivate: The case of Chinese EFL learners and the influence of culture on motivation. TESOL Quarterly, 39(4), p. 609-633. Retrieved from http://www.ingentaconnect.com.proxy.lib.pdx.edu/content/tesol/tq;jsessionid=1 $\mathrm{rdr}$ u78we97sk.alice

Chun, D. (2002). Discourse intonation in L2: From theory and research to practice. Philadelphia: John Benjamins Publishing Company.

Couper, G. (2003). The value of an explicit pronunciation syllabus in ESOL teaching. Prospect 18, 53-70. Retrieved from http://www.ameprc.mq.edu.au.proxy.lib.pdx.edu/docs/prospect_journal

Couper-Kuhlen, A. (2007). Situated phonologies: Patterns of phonology in discourse context. In M.C. Pennington, Phonology in context, (p. 186-218). New York, NY: Palgrave Macmillan.

Cruttenden, A. (2007). Intonational diglossia: a case study of Glasgow. Journal of the International Phonetic Association 37(2), p. 257-274. doi:10.1017/S0025100307002915

Diresta, D. (2001). Does uptalk make you upchuck? Retrieved from http://ezinearticles.com/?Does-Uptalk-Make-you-Upchuck?\&id=959

Dowhower, S.L. (1987). Effects of repeated reading on second grade readers' fluency and comprehension. Reading Research Quarterly, 22(4), p. 389-406. Retrieved from 
http://www.jstor.org.proxy.lib.pdx.edu/action/showPublication?

journalCode=readresequar

Dowhower, S.L. (1991). Fluency's unattended bedfellow. Theory into Practice, 30(3), p.

165-175. Retrieved from http://www.jstor.org/action/showPublication?

journalCode=theointoprac

Dung, D.T., Huong, T.T. \& Boulakia, G. (1998). In Hirst, D., \& Di, C. A. (Ed.s),

Intonation systems: A survey of twenty languages (p. 395-416). Cambridge, U.K:

Cambridge University Press.

Flynn, C.Y.C. (2003). Intonation in Cantonese. Muenchen, Germany: LINCOM GmbH.

Ford, C.E.\& S.A. Thompson. (1996). Interactional units in conversation: Syntactic, intonational, and pragmatic resources for the management of turns. In E. Ochs, E.A. Schegloff, \& S.A. Thompson (Ed.s), Interaction and grammar (p. 134-184). Cambridge, UK: Cambridge University Press.

Freelon, D. (2011). ReCal3 0.1 (alpha). Retrieved from http://dfreelon.org/recal/recal3.php

Gim, S. Chapter XVIII: Intonation. In Phonetics of Korean, (p. 92-95). Sŏul-si: Hanul.

Gumperz, J.J. (1982). Interethnic communication. In Discourse strategies (p. 172-186). New York: Cambridge University Press.

Hemingway, E. (2007). Hills like white elephants complete story - by Ernest Hemingway | machete. Retrieved from http://www.gummyprint.com/blog/archives/hills-likewhite-elephants-complete-story/ 
Hudson, R.F., Lane, H.B., \& Pullen, P.C. (2005). Reading fluency assessment and instruction: What, why, and how? The Reading Teacher, 58(8), p. 702-714. doi:10.1598/RT.58.8.1

Jackson, S. (2008). One ordinary day, with peanuts by Shirley Jackson. Retrieved from http://members.multimania.co.uk/shortstories/jacksonordinaryday.html

Laan, G.P.M. (1997). The contribution of intonation, segmental durations, and spectral features to the perception of a spontaneous and a read speaking style. Speech Communication, 22, p. 43-65. doi:10.1016/S0167-6393(97)00012-5

Ladd, D. (1980). Intonation and Grammar. In The structure of intonational meaning (p. 139-168). Bloomington, IN: Indiana University Press.

Ladd, D. (2008). Intonational phonology: Second edition. Cambridge: Cambridge University Press.

Ladefoged, P. (2006). Chapter 5: English words and sentences. In A course in phonetics (p. 107-132). Boston, MA: Wadsworth, Cengage Learning.

Lammers, W.P. (2005). Japanese: the manga way. Berkeley, CA: Stone Bridge Press.

Levis, J.M. (2005a). Comparing apples and oranges? Pedagogical approaches to intonation in British and American English. Linguistic Insights, 21, p. 339-366.

Levis, J.M. (2005b). Changing contexts and shifting paradigms in pronunciation teaching. TESOL Quarterly, 39(5), p. 369-377. Retrieved from http://www.ingentaconnect.com.proxy.lib.pdx.edu/content/tesol/tq;jsessionid=1rdr u78we97sk.alice 
Lipson, M.Y. \& Lang, L.B. (1991). Not as easy as it seems: Some unresolved questions about fluency. Theory into Practice, 30(3), p. 702-714. Retrieved from http://www.jstor.org/action/showPublication?journalCode=theointoprac

Lowry, O. (2002). The stylistic variation of nuclear patterns in Belfast English. Journal of the International Phonetic Association, 32(1), p. 33-42. doi:10.1017/S0025100302000130

Markus, M. (2008). The relevance of spoken features in English as a foreign language (EFL). English Today, 24(4), p. 17-25. doi: 10.1017/S0266078408000357

Meng, X.J., \& Wang, H.M. Boundary tone patterns in Chinese English learners' read speech. Foreign Language Teaching and Research (bimonthly), 41(6), p. 447-451.

Miller, J. \& Schwanenflugel, P.J. (2008). A longitudinal study of the development of reading prosody as a dimension of oral reading. Reading Research Quarterly, 43(4), p. 336-354. doi:10.1598/RRQ.43.4.2

Morley, J. (1991). The pronunciation component in teaching English to speakers of other languages. TESOL Quarterly 25(3), p. 481-520. Retrieved from http://www.jstor.org.proxy.lib.pdx.edu/action/showPublication? journalCode=tesolquarterly

Morley, J. (1994) A Multidimensional Curriculum Design for Speech-Pronunciation Instruction. In J. Morley (Ed.), Pronunciation Pedagogy and Theory: New Views, New Directions (p. 64-91). Alexandria, VA: TESOL. 
Ngo, B.N. (2003). Pronunciation guide. In Elementary Vietnamese: Revised edition. (p. 21-40). North Clarendon, VT: Tuttle Publishing.

Pinter, H. (1977). The Collection. In Complete works: Two (p. 119-157). New York, NY: Grove Press, Inc.

Portland State University. (2010, November 5). Intensive English Language (ESL) Program - IELP - at Portland State University | About Us. Retrieved from http://www.ielp.pdx.edu/about.php

Ramsey, R.S. (1987). Today's Dialects. In The languages of China (p. 87-115). Princeton, NJ: Princeton University Press.

Romero-Trillo, J. \& Llinares-García, A. (2004). Prosodic competence in reading aloud: An acoustic corpus-based study of native and non-native (Spanish) speakers of English. Estudios Ingleses de la Universidad Complutense, 1263(77), p. 63-77. Retrieved from http://www.ucm.es/BUCM/revistasBUC/portal/modules.php? name $=$ Revistas $2 \& \mathrm{id}=\mathrm{EIUC}$

Rui, T. (2007). The English intonation of Chinese EFL learners: A comparative study. CELEA Journal, 30(6), p. 34-45. Retrieved from http://www.celea.org.cn/

Sachs, G.T. \& Mahon, T. (1997). Reading in English as a foreign language: Primary students' oral reading behaviour and comprehension. Perspectives, 9, p. 78-109. Retrieved from http://sunzi1.lib.hku.hk/hkjo/issue.jsp?book=10

Shen, X.S. (1990). The prosody of Mandarin Chinese. University of California Press: Berkeley. 
Slowiaczek, M.L., \& Clifton, C. (1980). Subvocalization and reading for meaning. Journal of Verbal Learning and Verbal Behavior, 19, p. 573-582. doi: 0022$5371 / 80 / 050573-10502.00 / 0$

Texasoft. (2008). Interrater reliability (kappa) using SPSS. Retrieved from http://www.stattutorials.com/SPSS/TUTORIAL-SPSS-Interrater-ReliabilityKappa.htm

Thompson, L.C. (1987). An introduction to Vietnamese pronunciation. In A Vietnamese reference grammar, (p. 3-17). Honolulu: University of Hawai'i Press.

Tsujimura, N. (1996). Chapter 3: Phonology. In An introduction to Japanese linguistics, (p. 23-124). Cambridge, MA: Blackwell Publishers Inc.

Underhill, A., Ed. (1994). Level 3: Connected speech. In Sound Foundations. (p. 58-94). Oxford: Heinemann English Language Teaching.

Wells, J.C. (2006). English intonation: An introduction. New York, NY: Cambridge University Press.

Wennerstrom, A. (2001). Intonation and evaluation in oral narratives. Journal of Pragmatics, 33, p. 1183-1206. doi:10.1016/S0378-2166(00)00061-8

Wolff, R.A. (2000). Portland dialect study: High rising terminal contours (HRTS) in Portland speech (Unpublished master's thesis). Portland State University: Portland, OR. 
Yamato, K. (2004). Realization of illocutionary force through English intonation by Japanese EFL learners. Prospect: The Journal of the Adult Migrant Education Program 19(3), p. 56-73.

Yavaş, M. (2006). Structural factors in second language phonology. In Applied English Phonology. (p. 177-210). Malden, MA: Blackwell Publishing. 


\section{Appendix A: Initial Session Questionnaire}

The extra questions given in parentheses were sometimes used to clarify the response further. This modified questionnaire is based on one used at UCLA (CelceMurcia, et al., p. 396-397). Some questions were altered to make them applicable to PSU, and others were clarified. Two questions were added. One added question asks about intonation in particular. In addition to giving the students a chance to address any concerns they may have, the other question attempts to elicit any of the different intonation contours associated with questions.

1. What is your native language? (Which dialect do you speak?)

2. What year in school are you?

3. How long have you been at PSU?

4. How long have you been in the US?

5. Have you taken any previous trips to US or other English-speaking countries?

6. What percentage of time do you speak English each day?

7. Describe your experience learning English. (How have you learned English? How were you taught English before?)

8. Which English accent are you most familiar with?

9. Have you been taught pronunciation before? Please give details.

10 . Why do you want to work on pronunciation?

11. How do you expect to use English in the future? (What is your major? What kind of job do you want to have after you finish school?) 
12. Please describe a situation in which Americans misunderstood you because of your pronunciation.

13. Have you ever asked an American for help with pronunciation? (How did they help you?)

14. Is there a particular situation in which you get particularly nervous about pronunciation?

15. In what situation do you feel most comfortable speaking English?

16. What are your biggest pronunciation problems in English?

17. Have you been taught about English intonation before? (If so, how did the teacher teach you? Did the teaching help you with your intonation?)

18. Do you have any questions for me? (Do you have any questions about the tutoring before we start?) 


\section{Appendix B: Exit Interview Questions}

The semantic differential scale in question 4 was adapted from Ghaith (2001, p. 299). In the actual interview, the tables for question 4 were provided on separate pieces of paper for the students to circle their answers.

1. During the tutoring sessions, did you learn from:

a. seeing the drawings of the intonation patterns?

b. listening to the explanations of the intonation patterns?

c. practicing with oral reading?

d. having your intonation patterns corrected by the teacher?

2. What did you think could have been better about the tutoring sessions? What could the teacher have done better in the tutoring sessions?

3. What should the teacher keep the same in the tutoring sessions (for future students)?

4. What are your feelings about studying...

a. ...English through oral reading? Please choose a number on each of the four scales below:

\begin{tabular}{|l|l|l|l|l|l|l|l|}
\hline Useful & 1 & 2 & 3 & 4 & 5 & 6 & Useless \\
\hline Frustrating & 1 & 2 & 3 & 4 & 5 & 6 & Not Frustrating \\
\hline Not Fun & 1 & 2 & 3 & 4 & 5 & 6 & Fun \\
\hline Interesting & 1 & 2 & 3 & 4 & 5 & 6 & Boring \\
\hline
\end{tabular}


b. ...English intonation patterns? Please choose a number on each of the four scales below:

\begin{tabular}{|l|l|l|l|l|l|l|l|}
\hline Useful & 1 & 2 & 3 & 4 & 5 & 6 & Useless \\
\hline Frustrating & 1 & 2 & 3 & 4 & 5 & 6 & Not Frustrating \\
\hline Not Fun & 1 & 2 & 3 & 4 & 5 & 6 & Fun \\
\hline Interesting & 1 & 2 & 3 & 4 & 5 & 6 & Boring \\
\hline Confusing & 1 & 2 & 3 & 4 & 5 & 6 & Clear \\
\hline
\end{tabular}

5. Have you seen any changes in your pronunciation as a result of these tutoring sessions?

(What changes have you seen in your pronunciation?)

6. Has your understanding of intonation in English changed as a result of these tutoring sessions? (How so?)

7. Would you recommend that a friend get this kind of tutoring? (Why?/Why not?)

8. Will you change your pronunciation as a result of this instruction? 


\section{Appendix C: Description of a typical tutoring session}

Note: The following section describes what a typical tutoring session looked like (from my perspective as the tutor/researcher), with Long, a Vietnamese student, as a typical tutee. I do not describe exactly how one particular session went but rather what generally occurred during the sessions.

Before Long arrived, I went to the library circulation desk and checked out a study room key. I met him at the front doors of the library, and we went to our study room. The room was small and windowless, but at least it was quieter than outside. I took out "The Martian Chronicles" by Ray Bradbury from my backpack before I sat down. Long sat next to me. I consulted the tutoring log to see which page Long read up to in the last session. Before we began reading, I asked Long to explain the four basic intonation patterns that we had been working on. He provided examples of the four patterns with little difficulty, although he forgot the name of one of the patterns. We reviewed the point that intonation has discourse functions in terms of signaling how a speaker feels, showing if a speaker is finished with his/her turn, and marking how certain a speaker feels about what he/she is saying. I asked Long to tell me what kind of intonation is normally used on tag questions versus how the intonation changes when a speaker wishes to assert something.

Then we reviewed what had already happened in the story we were reading. Long said that he was concentrating more on correct pronunciation than on the meaning of the story when he read, so I summarized the plot so far. In the story from "The Martian Chronicles" that we were reading, I highlighted the conflict between the main characters, 
Mr. and Mrs. K, and we reviewed how Mrs. K's dream caused Mr. K to become very upset. The initial review of intonation patterns and the quick recap of the story took just over five minutes.

Next, we began what took up the bulk of the intonation tutoring time: reading aloud by Long. Sometimes I stopped him to discuss the plot or point out differences between how he read a sentence and how I would read it. I tried not to stop him more than once a paragraph, but some dialogue sections required frequent intervention. (Generally, I interrupted him much more often in the earlier teaching sessions than in the later ones because his grasp of the intonation patterns improved.) For example, when $\mathrm{Mr}$. $\mathrm{K}$ was very angry with his wife, he was likely to put a falling intonation on his tag questions, showing both how certain he felt and how upset he was. Long seemed to understand what the default contours are for various sentence types, but sometimes I felt it necessary to point out how the role that a particular utterance plays in the discourse may override what the default contour is. When I noticed sentence types that have intonation contours that we had not discussed yet, I pointed out what those were. For example, I explained to him how compound sentences usually fall at the end like a definite statement, but in the middle, on the last syllable before the conjunction, there is usually a fall-rise. In the sentence, "I want to go, and you don't," the word "go" has a falling-rising intonation, showing that the speaker has more yet to say, that the sentence is unfinished. (Note: the oral reading pre- and post-tests only assessed part of what was covered in the teaching interventions because of the difficulty of assessing discourse functions.) 
In Long's case, there was much transfer from his L1 phonological system into English. This transfer is especially apparent when a voiceless stop such as $/ \mathrm{p} /, \mathrm{t} /$, or $/ \mathrm{k} /$ appeared at the end of a syllable. I pointed out to Long that he usually said syllables with final consonants like these with a high tone at the end, but that tone is often not natural in English, especially at the end of definite statements. I explained to him that, in Vietnamese, voiceless stops at the end of syllables give the syllable a high tone, but that in English, the tone at the end of a sentence is determined by syntax and discourse functions.

After about 30 minutes of intonation tutoring (including initial review and oral reading practice), I asked Long to stop reading at a natural break in the story and noted in the teaching log where we had stopped. I then told him what he still needed to work on in terms of intonation, specifically, how accurate his choice of intonation patterns was, such as if he needed to concentrate on using the correct contour for a particular pattern. I also asked him for feedback on the story that we were reading. He said that the story was fine, but he felt that sometimes the sentences used unnatural grammar. I explained to him that the writer liked to use layers of description rather than saying what he meant more directly in one short sentence. Although Long disliked that aspect of the story, he declined my offer of changing to a different story in the next session.

In the other half of the tutoring session (the last 30 minutes), I corrected one of Long's political science papers. I noted consistent grammatical errors that he was making. When the corrections were complete, Long thanked me for my help, and I thanked him for his help with my research. I confirmed the meeting time with him for the next week 
Running head: TEACHING INTONATION PATTERNS... 102

before he left. When he was gone, I made notes in the teaching log about what we had covered, and I also jotted down the comments that Long made about the instruction he received, including what he said about the writing style of the short story we read. 


\section{Appendix D: Modifications to "Bliss" (Pre-test Text)}

The following text of Bliss shows the modifications I made to the text to make it easier for the participants to read and to give it the required number of each sentence type. Strikethrough indicates deletions; underlining indicates additions. Minor changes to punctuation and spelling are not shown.

\section{Bliss}

by Anton Chekhov, translated by Marian Fell

It was midnight. Suddenly Mitia Kuldaroff burst into his parents' house, dishevelled his hair and clothes a mess and he was very excited, and he went flying through all the rooms. His father and mother had already gone to rest; his sister was in bed finishing the last pages of a novel, and his school-boy brothers were fast asleep.

"What brings you here?" cried his astonished surprised parents. "What is the matter? You aren't drunk are you?"

"Oh, don't ask me! I never expected anything like this! No, no, I never expected it! It isit is absolutely incredible!"

Mitia burst out laughing and dropped into a chair, unable to stand on his feet from happiness.

"It is incredible!, isn't it? You can't imagine what it is! Look here!"

His sister jumped out of bed, threw a blanket over her shoulders, and went to her brother. The schoolboys woke up-

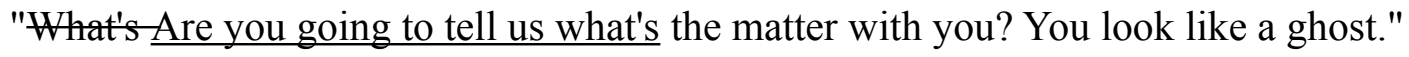


"It's because I'm so happy, mother. I am known all over Russia now. Until today, you were the only people who knew that such a person as Đimitti Mitia Kuldaroff existed, but now all Russia knows it! Oh, mother! Oh, heavens!"

Mitia jumped up, ran through all the rooms, and dropped back into a chair.

"But what has happened? Talk sense, won't you!"

"You live like wild animals, you don't read the news, Do you read the news? No! The press media is nothing to you, and yet there are so many wonderful things in the papers! Everything that happens becomes known at once, nothing remains hidden! Oh, how happy I am! Oh, heavens! The newspapers only write about famous people, and now there is something in them about me! This is great, isn't it?"

"What do you mean? Where is it?"

Papa turned pale. Mamma glaneed at the ieon and erossed herself. The schoolboys jumped out of bed and ran to their brother in their short night-shirts.

"Yes, sir! There is something about me in the paper! The whole of Russia knows it now. Oh, mother, keep this number as a souvenir; we can read it from time to time. Look!" Mitia pulled a newspaper out of his pocket and handed it to his father, pointing to an item marked with a blue pencil.

"Read that!"

His father put on his glasses.

"Come on, read it $\div$, won't you?"

Mamma glaneed at the ieon onee more, and erossed herself looked nervous. Papa cleared his throat, and began: 
"At 11 PM, on December 27, a young man mitia Kuldaroff-" "See? See? Don't you see? Go on!"

"A young man by the name of Dimitri named Mitia Kuldaroff, coming out of a tavern bar on Little Armourer A Street, and being in an intoxieated eondition drunk-"

"That's it, I was with Simon Petrovitch! Every detail is correct. Go on! Listen!"

"-being sliped and fell under the feet of a horse -

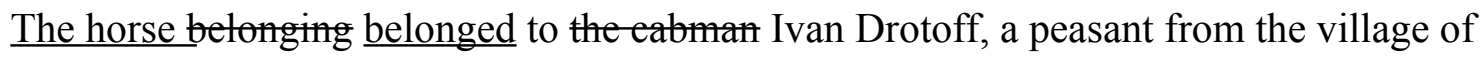
Durinka in the provinee of Yuknofski. The frightened horse jumped across Kuldaroff's prostrate body, pulling the sleigh after him. In the sleigh sat Stephen Lukoff, a merchant of the Second Moscow Guild of Merehants Company. The horse galloped ran down the street, but was finally stopped by some house porters men. For a few moments Kuldaroff was stunned. He was taken to the police station and examined by a doctor. The blas he of the neck-"

"That was from the shaft bottom of the sleigh, Papa. Go on! Read the rest!"

"- the blow which he had ststained on the back of the neck was pronouneed to be slight, but the doctor said the damage was slight. The victim was given medical assistance."

"They put eold-water bandages around my neck. Do you believe me now? What do you think ? Isn't it great? It has gone all over Russia by now! Give me the paper!" Mitia seizabed the paper, folded it, and put it into his pocket, exclaiming: 
"I must run to the Makaroffs, and show it to them! This is so exciting, isn't it? Are you excited? And the Ivanoffs must see it, too, and Natalia, and Ana-I must run there at once! Good-bye! "

Mitia erammed put on his cap and ran blissfully and trimmphantly happily out into the street.

Retrieved from http://en.wikisource.org/wiki/Bliss 